\title{
Exploring the influence of the North Pacific Ocean Rossby wave sources on interannual variability of summer precipitation and surface temperature over the Northern Hemisphere.
}

Ramon Fuentes-Franco ( $\nabla$ ramon.fuentesfranco@smhi.se )

SMHI https://orcid.org/0000-0002-3085-0175

\section{Torben Koenigk}

SMHI: Sveriges meteorologiska och hydrologiska institut

\section{David Docquier}

SMHI: Sveriges meteorologiska och hydrologiska institut

\section{Federico Graef}

CICESE: Centro de Investigacion Cientifica y de Educacion Superior de Ensenada

\section{Klaus Wyser}

SMHI: Sveriges meteorologiska och hydrologiska institut

\section{Research Article}

Keywords: Rossby wave sources, Northeastern Pacific Ocean, summer, negative temperature anomalies, positive temperature anomalies

Posted Date: February 20th, 2021

DOI: https://doi.org/10.21203/rs.3.rs-169409/v1

License: (c) (i) This work is licensed under a Creative Commons Attribution 4.0 International License.

Read Full License 


\section{Abstract}

The influence of Rossby wave sources (RWS) emitted on the Northeastern Pacific Ocean in the Northern Hemisphere during summer is analysed in the ERA5 reanalysis and new large ensemble performed with the EC-Earth3 model. Using extreme years composites of precipitation, surface temperature, geopotential height, we found a causal influence of the Rossby waves generated over the Northeastern Pacific Ocean, on a global climate response. Both the reanalysis ERA5 and the EC-Earth3 model show that RWS triggers wave-like patterns arising from the upper troposphere Northeastern Pacific region. We show that an increased Rossby wave sources intensity is related with negative temperature anomalies over western North America, and positive temperature anomalies over eastern North America concurrently increased precipitation over Northern Europe during summer and sea-ice concentration decrease in the Arctic. We also show that the North Atlantic plays a very important role hindering or permitting that Rossby waves generated in the Pacific reach the Atlantic and modulate the atmospheric conditions over Europe. Such conditions were found in ERA5 and SMHI-LENS during colder and icier conditions over the North Atlantic.

\section{Introduction}

Circumglobal Rossby waves influence strongly the meandering of the jet stream in the mid-latitudes around the globe, and therefore they have been associated with strong variability of precipitation during summer (Kornhuber et al. 2019) and winter seasons (Scaife et al. 2017b, Dunstone et al. 2018, Li et al. 2019). Rossby waves appear in the atmosphere as a result of vertical motion and upper-tropospheric divergence in the tropics causing in turn anomalous upper-level vorticity. Since this upper-level vorticity induces the formation of Rossby wave trains, Sardeshmukh and Hoskins (1988) called it Rossby wave sources (RWS). RWS are one of the mechanisms responsible for the teleconnections (Qin and Robinson, 1993).

Due to the strong impact of Rossby waves on the extratropical weather and climate, it is relevant to study the geographical places that act as sources. In this context, Nie et al. (2019) analysed the observed average spatial location of the RWS during winter and summer, finding that during winter, the main RWS in the Northern Hemisphere are located in East Asia, subtropical central and eastern Pacific, North America, subtropical North Atlantic, Mediterranean, and Arabian regions; while during summer over the Mediterranean, Arabian, and over the Eastern Pacific close to North America. Nie et al. (2019) also assessed how some CMIP5 models simulate the intensity and location of RWS in the historical period, finding that CMIP5 models can capture the basic geographical distribution of RWS, but most models overestimate the RWS intensity in the subtropics and underestimate the RWS in the midlatitudes.

Rossby waves are the mechanism behind concurrent periods of above normal temperature around the globe, causing heat waves in North America, Western Europe and the Caspian Sea region (Kornhubet et al. 2019). Petoukhov et al $(2013)$ and Kornhuber et al. $(2017,2020)$ showed that Rossby waves with a preferred size (wavenumber 5 -7) and phase position, constitute recurrent atmospheric circulation patterns. According to Kornhuber et al. (2017), this preferred position and phase of the waves can be 
explained by the shape of the continents and oceans and the geographical position of prominent orographic features (like the Rocky Mountains and the Ural Mountains in the Northern Hemisphere), which cause surface temperature differences. In general, a change in the direction of the north-to-south wind is coincident with continental west coasts in the Northern Hemisphere, with, for example, northward winds onshore and southward winds offshore or vice versa. In this context, when there are hightemperature anomalies over land in the vicinity of the coastline a north-to-south component of the wind is set, due to thermal wind relation. The interaction of the jet stream with cyclonic and anticyclonic systems causes co-variability of weather in far-away regions (Branstator 2002, Kornhuber et al. 2020), like the summers of 2006 and 2018 with dry conditions over western Central North America, Western Europe and Western Asia, or in 2012 with dry conditions over Central North America and Eastern Europe.

These concurrent extreme dry (or wet) periods over different parts of the world caused by stalled Rossby waves seem to be more frequent in the last twenty years. Before the year 2000, Kornhuber et al. (2017) found only 3 cases, and after 2000, they found 6 .

Up to now, it has been a challenge to find strong linkages between teleconnection indices and the interannual variability of precipitation over Northern Europe (NE). One of the main teleconnection patterns having a strong impact over NE is the North Atlantic Oscillation (NAO), which is a phenomenon arising from midlatitude eddy-mean flow interaction. According to Feldstein (2003), this interaction can be triggered by Rossby waves propagating from the Tropics. Scaife et al. (2017b) showed that tropical rainfall explained $40 \%$ of the variance in the seasonal forecast of the NAO through Rossby waves. Further evidence for wave-like patterns associated with seasonal precipitation and the possible origins for these waves have been found to give a better understanding of process-based teleconnections of the European climate interannual variability. For example, Knight et al. (2017) suggested that the mechanism responsible for very wet winters in Northwestern Europe was the occurrence of Rossby waves generated over the Amazon region and the Tropical North Atlantic Ocean.

In turn, Li et al. (2019) identified as potential Rossby wave source regions the Tropical Atlantic, the subtropical eastern Atlantic and, to a smaller degree, the subtropical eastern Pacific, especially over the Gulf of California. They found that about $60 \%$ of the European wet and dry events were significantly influenced by tropical precipitation anomalies.

Some of the teleconnections modulating the climate variability over Eurasia can be caused by tropical forcing, which causes an atmospheric response that propagates polewards (e.g., Hoskins and Ambrizzi, 1993; Van Oldenborgh et al., 2000; Ding et al, 2011, Gastineau and Frankignoul 2015, Wulff et al. 2017, O'Reilly et al. 2018, Neddermann et al. 2019), for example, the circumglobal teleconnection pattern (CGT, Barnstator et al. 2002).

Particularly for Europe, Wulff et al (2017) showed some evidence that the summer east Atlantic mode, which modulates the precipitation over the North Atlantic (NA) west of the British Isles, is forced by diabatic heating anomalies of opposing signs in the tropical Pacific and Caribbean. An important source of predictability for northern European climate from the Pacific has been also found by Fuentes-Franco 
and Koenigk (2020), who showed evidence of a large scale link between the tropical atmospheric variability over the central tropical Pacific during spring and the atmospheric circulation over the western Arctic and the North Atlantic-European sector during summer, which ultimately impacts the precipitation especially over Northern Europe (NE). This teleconnection mechanism, which in early spring has a similar spatial structure to the Pacific North American pattern, shows an atmospheric expansion in middle levels of the troposphere $(500 \mathrm{hPa})$ in the central subtropical Pacific, west of Hawaii, is followed by cooler and wetter than normal summers over NE. Fuentes-Franco and Koenigk (2020) showed that this seasonallylagged teleconnection shows global systematic changes such as a strong anticyclonic flow and a decrease of sea ice concentration over the western Arctic, as well as higher atmospheric pressure and drier conditions over the European coasts of the eastern Mediterranean.

It has been found that Rossby waves impacting the atmospheric circulation of the North Atlantic and European sectors seem to be generated by SST anomalies over the Gulf of Mexico and the Pacific (Saeed et al., 2014; Wulff et al., 2017; Neddermann et al., 2019). However, the potential impact of Rossby waves generated in the Pacific Ocean on the European climate has not been studied yet. In this paper we will investigate the role of RWS maximum over the Pacific on the global atmospheric circulation, focusing in particular on its impact on the interannual variability of precipitation over NE during summer. Using a large ensemble of simulations, we will also assess the reproducibility of a potential relationship between RWS maxima and interannual variability of precipitation over NE, in the context of internal variability. In Section 2, we describe the applied methodology and data used. The results and discussion are presented in Section 3 and summarized in the conclusions in Section 4.

\section{Methods And Data Used In This Study}

\subsection{Rossby Wave Sources (RWS)}

Similarly to Scaife et al. (2017b) and Nie et al. (2019), the RWS were derived from the barotropic vorticity equation in pressure coordinates as in Sardeshmukh and Hoskins, 1988; James, 1994, Trenberth et al (1998) and Holton and Hakim (2004). The Rossby wave activity can be calculated from horizontal winds $\left(v_{x}\right)$ :

$$
R W S=-\nabla \cdot\left(v_{x} \zeta\right)=-\left(\zeta \nabla \cdot v_{x}+v_{x} \cdot \nabla \zeta\right)
$$

with $\zeta$ being the absolute vorticity. Therefore the RWS accounts for the rate of change of vorticity due to vortex stretching (first term) and to the vorticity advection by the divergent part of the wind (second term). According to Scaife et al. (2017b), when analysing seasonal scales of RWS calculated at 200hPa, using monthly data of wind show very similar results than using daily data. For comparison, we calculated the RWS from daily and monthly data. Scaife et al. (2017b) used the horizontal wind at $200 \mathrm{hPa}$ since the RWS intensity peaks at that atmospheric level, in which strong convective outflow, divergent horizontal flow, and a strong vorticity gradient near the upper-tropospheric peak in the strength of the jet streams. 


\subsection{Data}

To calculate RWS we use the wind at $200 \mathrm{hPa}$, and to analyse the impact of RWS on the atmosphere we use geopotential height at $500 \mathrm{hPa}$, precipitation and surface temperature from the European Centre for Medium-range Weather Forecasts (ECMWF) ERA5 reanalysis [Copernicus Climate Change Service (C3S), 2017] during summer (June to August). This reanalysis has a horizontal resolution of approximately 31 $\mathrm{km}$. We use 40 years from 1979 to 2018. We also use sea ice concentration from the Version 2 of the EUMETSAT OSI SAF satellite observations (Lavergne et al. 2019).

Internal atmospheric variability connected with annular modes of circulation variability is the largest source for uncertainties in mid and high latitudes, therefore to analyse the representation of the RWS, and the impact of the regions with maximum RWS on the atmospheric circulation, considering internal variability, we used the Swedish Meteorological and Hydrological Institute Large Ensemble (SMHI-LENS, Wyser et al. submitted), which is a 50-member set of simulations performed with the EC-Earth3 model (Döscher et al. submitted). The use of a large number of ensemble members allows to statistically distinguish the modulation caused by RWS maxima on precipitation and atmospheric circulation from internal variability (Deser et al. 2012, Horton et al. 2015).

\subsection{Relationship between interannual variability of RWS with other global variables}

From the 40 years of ERA5 reanalysis, for precipitation, surface temperature and geopotential height at $500 \mathrm{hPa}(\mathrm{z} 500)$, and OSI SAF sea ice concentration, we created composites of mean seasonal anomalies of the four summers with most intense RWS activity ( $90^{\text {th }}$ percentile, p90), and the four summers with weakest RWS activity $\left(10^{\text {th }}\right.$ percentile, $\left.\mathrm{p} 10\right)$, generated over the Pacific. To assess the amplitude of the RWS signal on the different variables, we calculated the difference between the p90 and p10 composites for every variable.

The statistical significance of the seasonal anomalies was calculated using a bootstrap technique (resample with replacement, with 1000 repetitions) (Efron and Tibishrani, 1991) to determine the likelihood of the value occurring by chance.

After having the 1000 repetitions (of 4 random-summer composites minus 4 random-summer composites), the statistical significance of the occurrence of extreme seasonal anomalies is computed by counting the number of extreme seasonal anomalies found during the RWS extremes and comparing them with the probability of this frequency of extreme seasonal anomalies occurring by chance. Besides the composite analyses, Pearson correlations were calculated between these seasonal RWS and global variables such as geopotential height at $500 \mathrm{hPa}$, precipitation, surface temperature and sea ice concentration, for both the ERA5 reanalysis and the SMHI-LENS, highlighting regions of coincidence in the sign of the correlation coefficients.

\section{Results And Discussion}




\subsection{Impact of Pacific RWS on the Northern Hemisphere climate in ERA5}

The geographical distribution of the climatology of RWS over the Northern Hemisphere calculated from the ERA5 reanalysis shows that the RWS maxima during winter are located over the subtropical central Pacific, west of the Hawaiian archipelago (PacWH), Tropical North Atlantic (TNA), East Asia (EA), and over North African- Mediterranean area (NAfr), as shown in Figure 1a. In turn, during summer, in the Northern Hemisphere the RWS maxima are located over the Eastern Pacific extending from the central Pacific to the North American coasts (PacCal), the subtropical North Atlantic (TNA), the Mediterranean area (Medit), Middle East (MidEast) (Figure 1b). The main differences between winter and summer are that in the Pacific and Atlantic basins the maxima get constrained towards the easternmost part of the basins during summer compared to their more central location during winter. EA does not pop-up as a region of RWS maximum during summer, while MidEast does not appear to have a RWS maximum during winter. The NAfr region shown as a maximum RWS area during winter shows a northward displacement towards the Mediterranean region.

Our results show similarities with those of Nie et al (2019) for both seasons and with Lu and Kim (2004) during summer. Previously, Fuentes-Franco and Koenigk (2020) have found that the atmosphere over the Pacific Ocean seems to have a late-winter to summer seasonally-lagged impact over the Northern Europe climate variability, in such a way that atmospheric signals generated over the subtropical Pacific in late winter would cause consistent response over Northern Europe during summer. In Fuentes-Franco and Koenigk (2020), the region that serves as a predictor for precipitation over Northern Europe and that presumably generates atmospheric waves is located in the subtropical Pacific, west of Hawaii within the longitudes $180 \mathrm{~W}$ and $168 \mathrm{~W}$ and latitudes $18 \mathrm{~N}$ and $27 \mathrm{~N}$ (WH-z500), which shows geographical coincidence with the RWS maximum over the Pacific (PacWH) during winter. As the maximum solar radiation moves northward with the arrival of the summer season, the location of the RWS maxima over the Pacific moves northeastwards from the PacWH region in winter towards the North American coast during summer (PacCal region, Figure 1b).

The WH-z500 predictor during March shows also a high positive correlation with the RWS during March, especially within the area North of Hawaii $(\mathrm{NH})$, between the longitudes $168 \mathrm{~W}$ and $150 \mathrm{~W}$ and the latitudes $22 \mathrm{~N}$ and $27 \mathrm{~N}$, which lies in a location east of the climatological RWS maximum (PacWH region) during winter (Figure 2a), with correlation values exceeding $r>0.5$ for some gridpoints. The temporal correlation of the spatial average RWS over the NH during March and the spatial average RWS over the PacCal region during summer is $r=0.3$, being significant at $95 \%$ (Figure $2 b$ ). Therefore it seems to be that increased (or decreased) RWS over the central subtropical Pacific (specifically over NH) would increase the likelihood of increased (decreased) RWS in the summer over the PacCal region. Both the RWS over NH and the WH-z500 show similar patterns of high correlation with RWS during summer over the PacCal region, especially close to the North American coast (Figure 3). Understanding the reasons why there is persistence of RWS from late winter to summer is out of the scope of this paper; however, further investigation should be carried out so that we better understand how a fast atmosphere shows interseasonal persistence of large scale signals. We assume that the ocean forcing would play an important 
role in the RWS intra-seasonal behaviour; however, we did not find a strong correlation between RWS with ENSO, nor with IPO.

The global teleconnection index WH-z500 reported by Fuentes-Franco and Koenigk (2020), shows a significant correlation with the RWS over the PacCal region ( $r=0.44$ with $p>99 \%$ ), therefore we further analysed the PacCal region as a potential modulator for the global atmosphere with particular focus over the NE region.

To analyse the global impact of PacCal RWS, we calculated the RWS p90 minus p10 composite anomalies of $z 500$, precipitation, surface temperature and sea ice concentration during July (Figure 4). The regions with significant p90 and p10 anomalies were obtained as described in section 2.3. For the p90, we used the years 1981, 1993, 2010 and 2011, while for the p10 we used the years 1985, 1994, 2007 and 2014. The results hold for other percentiles like p75 minus p25 (not shown), showing similar patterns in the anomalies.

The $z 500$ composite shows a wave-like pattern with a series of regions with positive and negative $z 500$ values around the globe, starting from a significant positive z500 values over the eastern Northern Pacific, followed eastwards by negative z500 over western North America, positive z500 values over eastern North America, negative z500 over Northwestern Atlantic ocean, positive z500 over the eastern North Atlantic, negative z500 over the Norwegian Sea, positive z500 over Russia, negative z500 over the Laptev and the East Siberian Seas, lastly positive z500 values over eastern Siberia and the Sea of Okhotsk. We consider the eastward direction since the synoptic Rossby waves interact with the background flow, which is on average with an eastward direction, although the Rossby waves would in principle travel westward, with a weaker phase speed than the eastward background flow.

Regions with significant wet and cold anomalies are found over geographical areas coincident with negative z500 anomalies (Figure 4b, c), i.e. western North America, Northwestern Atlantic ocean, Northern Europe (Norway, Sweden, Germany, Poland and the Baltic countries), the central Arctic. And thus, areas with significant dry and warm anomalies are also coincident with areas with positive z500 anomalies, showing noisier patterns for precipitation.

If we consider every positive-negative pair as part of a single wave, this would imply that around five waves cover the whole Northern Hemisphere. Previously Kornhuber et al (2020) have also mentioned that Rossby waves with wavenumbers 5 and 7 have a preferred phase position and constitute recurrent atmospheric circulation patterns in summer. The wave-like pattern is somehow similar to the wavenumber 5 pattern shown by Kornhuber et al. (2020), who reported that with wavenumber 5, cooccurring heatwaves can be present over Central North America, Eastern Europe and East Asia. However, the pattern that Kornhuber et al. (2020) show is displaced towards the west compared to the patterns emerged from RWS coming from the PacCal region. Negative sea ice concentration anomalies are found over the Beaufort Sea and the western part of the Canadian Archipelago, while positive ice concentration anomalies are found over the Greenland sea and the Baffin Bay (Figure 4d). In agreement with previous results from Screen and Francis (2016), we find that significant anomalous temperatures over the Pacific 
ocean, similar to a negative phase of PDO, are related with a decrease in sea ice concentration. In the context of an increased RWS over the PacCal region, there is higher pressure over the North Pacific due to an expanded atmosphere (Figure 4a), therefore anomalous southerly winds occur over the central North Pacific, which advect warm air into the western Arctic. Screen and Francis (2016) argue that enhanced ice-loss-driven Arctic warming during PDO-, is partly due to the atmospheric circulation during PDO- is more effective than PDO+ at transporting sea-ice-driven temperature anomalies from the peripheral Arctic seas into the central Arctic. We assume that this happens due to a wave-like pattern produced by enhanced RWS.

Different regions around the Northern Hemisphere show significant impacts across different variables during RWS extreme years, thus showing features of a consistent global teleconnection modulated specifically by the RWS on the PacCal region. The relationship between RWS over PacCal and the different variables over regions that show strong impact during extreme years was also measured in a more general way across all the period available calculating the Pearson correlation between RWS and specific variables (see Table 1). For example, there is a positive and significant correlation with z500 over the eastern North Pacific and the eastern North Atlantic. There is also a negative correlation with surface temperature on the eastern North Pacific, showing a similar to a negative Pacific Decadal Oscillation. RWS over PacCal is positively correlated with surface temperature in eastern North America and negatively correlated with sea ice concentration in the Canadian Archipelago and the central Arctic (Figure 4c). Weaker correlations with surface temperature are also found over central (negative) and eastern Siberia (positive).

In Table 1 we also compare the correlation between the WH-z500 predictor and all the previously mentioned variables. We found that although the intensity of the correlation varies, the sign of the correlation is consistent for both WH-z500 and RWS variables. In general, RWS shows stronger correlations with all the mentioned variables than the WH-z500 predictor, except for precipitation over NE and Swedfin regions ( $r=0.56$ and 0.62 respectively). The coincidence of the sign of correlation across variables gives another indication that the RWS generated in summer is partially related to the circulation of the atmosphere already in early spring.

Besides testing the global response to RWS at monthly scale, specifically for July, we also tested the response of global variables to RWS at daily scale for June to August, looking especially at its impact on precipitation over NE. After calculating RWS at daily scale over the PacCal region, we used the 12-day running mean to compare RWS with average precipitation over NE. We used the 12-day running mean since this time length lies within the time window during which the atmosphere over Europe would be influenced by a synoptic Rossby wave emitted from the PacCal region, after travelling $~ 8500 \mathrm{~km}$ eastwards at a speed between $6-12 \mathrm{~m} / \mathrm{s}$, therefore taking between around 8 to 16 days to travel that distance from its emission point. We found that there were years showing consistent results with the monthly scale (i.e. showing similar spatial correlation patterns between PacCal RWS and z500, precipitation and surface temperature), for example, 1981, 1985, 1986, 1991, 1994, 1997, 1998, 2000, 2002, 2006, 2009 and 2016. Particularly, the summer of 1991 shows that an increased RWS activity over 
the PacCal region, together with increased precipitation, which peaks by June 25th. From mid-June, the RWS activity started to consistently decrease, showing two small peaks in the middle of July and the middle of August (Figure 5a). The precipitation (green line) follows closely the behaviour of the RWS activity (orange line) with a correlation of $r=0.73$ across the all the 1991 summer months, while $z 500$ (blue line) shows an inverse, almost mirrored response as expected (Figure 5a). The spatial pattern conformed by the temporal correlation between PacCal RWS and precipitation for every grid-point for summer of 1991 (Figure 5b) shows similarities to the distribution of precipitation anomalies for July (Figure 4b). Showing high correspondence on areas and signs of the correlation and anomalies respectively, summer of 1991 particularly shows a high correlation between RWS and precipitation over Northern Europe (including from west to east Ireland, the United Kingdom, Northern France, Belgium, Netherlands, Northern Germany and Poland, Sweden and the Baltic countries).

The pattern of correlation between PacCal RWS and geopotential height or precipitation (Figure 5b), is similar to the cases analysed by Kornhuber et al (2017) who showed how the circulation patterns giving conditions for heatwaves around the globe might be caused by wave resonance between a stationary wave and a free wave with the same wave-length, in which case the wave amplitudes are summed up and therefore cause concurrent heat waves in regions like western Canada/United States, Europe and Japan.

Although some of the years that show a high correlation between PacCal RWS and precipitation over Northern Europe at daily scale belong to different extremes at monthly scale (for example 1985 and 1994 belong to $p 10$ and 1981 belongs to p90 due to the PacCal RWS intensity), they all have in common a cold North Atlantic ocean (not shown), with negative values in the Atlantic Multidecadal Oscillation Index. In this regard, we found that when making surface temperature composites of 5 years sorted from the highest correlation between PacCal RWS and precipitation over Northern Europe, there is a general tendency (although not statistically significant) to show that composites with the highest correlation, have colder North Atlantic ocean and those showing lower correlation values have warmer North Atlantic ocean (not shown).

Clearly, the RWS over the PacCal region is not the only source of variability that influences daily scale variability of the atmosphere in the globe, including Northern Europe, since the shown relationship at daily scale (Figure 5) is not present across all years. Other sources of variability might be dominant in other years, depending on the state of the climate components. As this paper aims to assess the impact of RWS generated in the Pacific during summer, the analysis of other possible sources of variability is out of scope in this paper.

\subsection{Impact of Pacific RWS on Northern Hemisphere climate in the SMHI-LENS}

In this section, we analyse the SMHI-LENS to assess if the global response of the RWS generated over the Pacific is also reproduced in most of the 50 ensemble members. We first calculated the RWS over the 50 SMHI-LENS ensemble members. The ensemble average of the summer RWS climatology (Figure 6a) shows the geographical location of the four RWS as ERA5 (Figure 1b). However, when assessing the 
ensemble bias (Figure 6b), we found that the PacCal and Medit RWS are slightly underestimated, and the MidEast RWS is overestimated in the SMHI-LENS. The TNA RWS shows a bias close to zero, being the RWS that shows the most similarity with ERA5.

To assess the impact of PacCal RWS in the global atmosphere, particularly over NE, we repeated the bootstrap procedure performed with ERA5. In this case, we sorted the 2250 simulated summers (45 simulated years for each of the 50 ensemble members) according to the PacCal RWS intensity. As for ERA5, we used only the month of July. Since the SMHI-LENS has many more simulated summers than in the reanalysis, for every variable (z500, precipitation, surface temperature and sea ice concentration), we calculated the ensemble mean over 20 summers ( 99 $9^{\text {th }}$ percentile), one with the 20 lowest PacCal RWS (p01) and a second one with the 20 highest PacCal RWS (p99). Similarly to ERA5, we calculated the RWS p99 minus p01 composite anomalies of z500, precipitation, surface temperature and sea ice concentration during July at monthly scale. The regions with significant anomalies were obtained as described in section 2.3, however with an ensemble size of 20 members instead of 4 as used for ERA5. In this case, we decided to make use of the larger amount of summers available in the SMHI-LENS to represent the extremes, instead of p90 minus p10 as in ERA5; however, results are comparable.

For $z 500$, we find that the pattern that emerges is also a wave-like pattern (Figure 7a); however, the locations for positive and negative $z 500$ values are not exactly located as in ERA5 (Figure 4a). The main coincidences occur over the Northeastern Pacific, with a positive significant $z 500$ values, followed to the east by a negative $z 500$ values over the North American west coast, less significant in the SMHI-LENS than in ERA5. A positive significant anomaly appears over the North of central Canada, which in comparison to ERA5, is located too far north. It is followed by a weak but significant negative anomaly over the western North Atlantic, and a significant positive anomaly over the eastern North Atlantic in good agreement with ERA5, although in the SMHI-LENS, it covers even the Iberian peninsula, in contrast to ERA5 where it does not reach continental areas of Europe. The SMHI-LENS show a significant negative anomaly over Northern Europe and the Norwegian and Greenland Seas, covering a wider area than the negative anomaly found in ERA5 over Northern Europe. The last anomaly in which are coincident is a significant positive anomaly over Russia which appears displaced towards the Northeast compared to where it is found in ERA5. Farther east anomalies are not consistent between ERA5 and the SMHI-LENS.

Although the precipitation response over NE is not as strong in the SMHI-LENS as in ERA5, positive significant anomalies are shown over Norway, Sweden, Finland, Poland and some other eastern European countries (Figure 7b). Due to its homogeneous nature, for temperature wide areas of NE show consistent negative anomalies (Figure 7c). In contrast, southern Europe shows significant positive anomalies.

To better understand how is the global response to PacCal RWS at monthly and seasonal scales, and to assess how robust is the relationship across all the ensemble members, we calculated the monthly and seasonal correlation of RWS with z500 in ERA5 and all SMHI-LENS ensemble members. To extract consistency from the correlation patterns from the SMHI-LENS, we counted the number of members showing either negative or positive correlation patterns. The dominant correlation sign, given by the 
number of ensemble members with the same correlation sign agreement, was then compared with the ERA5 correlation pattern. We found that for ERA5 the PacCal RWS - z500 correlation, the monthly patterns of June and July show the same features of those found in the z500 composite shown in Figure 4a, with changes in August especially over the North Atlantic and East Asia (Figure 8). The SMHI-LENS, in this case, shows a more similar pattern to ERA5, than in the z500 composite for extreme PacCal RWS shown in Figure 7a, with July having the greatest agreement with ERA5. We observe that for all months and the seasonal mean, the closer the PacCal RWS the higher the agreement between SMHI-LENS and ERA5. Overall, there is a good agreement over the Pacific ocean and North America. However, from the Atlantic towards the east, the dominant pattern in the SMHI-LENS tends to show wider areas of the same sign of correlation compared to ERA5, which increases the lack of agreement in areas farther east.

Focusing over Europe, we observe that the negative correlation in ERA5 over Northern Europe is reproduced by most of the SMHI-LENS ensemble members for all the months, however, as mentioned before, a bit displaced towards the east.

Regarding the correlation patterns between precipitation and PacCal RWS, the seasonal (JJA) map shows higher agreement than any of the monthly maps (Figure 9), with an agreement in positive correlation over Southwestern Canada and Northwest US, negative over eastern North America, and two wide bands of positive correlation over the western North Atlantic and negative correlation over the eastern North Atlantic reaching Europe. Since for the monthly cases, the positive correlations over Europe are only reproduced with an eastward bias, due to the circulation bias response discussed for the z500 case, the seasonal mean is the only case where areas of coincidence over NE appear.

The temperature agreements follow the behaviour of z500 maps (Figure 10), however, it is worth mentioning that the SMHI-LENS, that there is a wide agreement across ensemble members on negative correlation between PacCal RWS with surface temperature anomalies over the eastern Pacific ocean, which extend towards the tropical regions. Although PDO and ENSO indices do not show any correlation with RWS over the PacCal region, our results from reanalysis and the SMHI-LENS indicate consistently that negative anomalies over the Pacific are intrinsically related to RWS over the Pacific. It is a matter of discussion whether the SST creates an atmospheric response or vice-versa. Since anticyclonic air circulation over the North Pacific contributing with increased wind stress which accelerates upper ocean currents contributing to cold SST anomalies such as those associated with cold PDO phase; conversely being also possible that cold SST anomalies over the Northeastern Pacific cause the mentioned corresponding circulation anomalies.

Regarding sea ice concentration (Figure 11), our results obtained from ERA5 and OSI SAF are in line with Screen and Francis (2016) since a decrease in sea ice concentration along the summer would be correlated with negative SST anomalies over the eastern North Pacific Ocean, showing the highest correlation in July and August. The SMHI-LENS also shows a negative correlation between sea ice concentration and PacCal RWS, however, the number of members barely reaches above half the ensemble size. 
To further explore the spread in the relationship between PacCal RWS and precipitation particularly over $\mathrm{NE}$, we calculated the mean absolute error (MAE) on the correlation between PacCal RWS and precipitation over NE. The ensemble mean of the correlation patterns between PacCal RWS with precipitation and z500 calculated on the five SMHI-LENS members with the lowest MAE (top5, or the 10th percentile) shows a more similar pattern (Figure 12a) to ERA5 (Figure 9), showing positive correlation values over NE, but also showing the wave-like patterns in the z500 correlation (Figure 12b) placed more similarly to ERA (Figure 8). When comparing to the whole SMHI-LENS mean for precipitation, the only region in the world that shows a difference in the correlation is the North Atlantic-European region, with negative correlation over the Labrador sea and positive correlation over $\mathrm{NE}$, while showing almost no change elsewhere in the world (Figure 12c). For z500, the changes also appear over the Labrador sea with positive correlation, negative correlations over NE and the eastern US coast, and positive correlation over Southern Europe that extends north-eastwards towards Russia (Figure 12d).

In order to understand the climate conditions that improve the relationship between RWS and NE precipitation, we also calculated the top 5 ensemble mean for surface temperature, sea ice concentration and precipitation climatologies, and subtract it to the whole SMHI-LENS mean (Figure 13). We found that the top 5 ensemble mean shows colder surface temperature and higher ice concentration over the North Atlantic than the whole ensemble mean, reaching a difference of $<-0.8 \mathrm{~K}$ in the Labrador sea and increased sea ice concentration over the Labrador and Greenland seas of more than $5 \%$ compared to the whole ensemble mean.

We then sorted the ensemble members by MAE, using linear regression and making 5-member ensemble mean (sorted by MAE), and we found that there is a tendency to show colder North Atlantic surface temperature (specifically the region between longitudes $57 \mathrm{~W}$ and $30 \mathrm{~W}$ and latitudes $54 \mathrm{~N}$ and $60 \mathrm{~N}$ ) with lower MAE, showing the top5 up to one degree colder than the whole SMHI-LENS mean (Figure 14a). Concurrently there is a tendency to show higher sea ice concentration with lower MAE, showing $1 \%$ more over the same North Atlantic area (Figure 14b).

Similarly to the results found in ERA5 at daily scale, the SMHI-LENS ensemble shows that a colder North Atlantic (especially a colder Labrador sea), might set the conditions for a stronger PacCal RWS impact over NE. We assume that the wave-like pattern emitted in the PacCal region, which is shown with agreement over North America in the SMHI-LENS, interacts with higher pressure over the Labrador sea due to colder conditions, which then contributes to lower surface pressure (and z500) over NE and the eastern US coasts, however, to better understand the role of the Labrador Sea and the North Atlantic on Rossby waves emitted from the Pacific ocean, idealized experiments should be carried out, which will be done in a separate paper from this study.

\section{Conclusions}

The consistency of the results coming from reanalysis and the EC-Earth large ensemble provides strong support for a causal influence of the Rossby waves generated over the Northeastern Pacific ocean on a 
global climate response. We show that increased RWS intensity is related with negative temperature anomalies over western North America, and positive temperature anomalies over eastern North America concurrently increased precipitation over Northern Europe during summer and sea-ice concentration decrease in the Arctic.

We also show that Pacific RWS also impact the global climate variability, particularly the interannual variability of precipitation and surface temperature over NE. Although the results obtained with the global climate model might be subject to an internal model bias regarding its atmospheric circulation, wave-like patterns arising from the upper troposphere Northeastern Pacific region are a consistent feature across the ensemble members.

We found clues suggesting that the North Atlantic plays a very important role hindering or permitting that Rossby waves emitted in the Pacific reach the Atlantic and modulate the atmospheric conditions over Europe. Such conditions were found in ERA5 and SMHI-LENS during colder and icier conditions over the North Atlantic. This modulating role of the North Atlantic should be further investigated. Likewise, further research on the possible future impacts of RWS in future projections across different models should be carried out.

\section{Declarations}

\section{Acknowledgment}

ERA5 dataset was downloaded from the Climate Data Store (CDS) of the European Centre for Medium Range Weather Forecasts (ECMWF-ERA5). This work was carried out using resources provided by the Swedish National Infrastructure for Computing (SNIC) at the National Supercomputer Centre at Linköping University (NSC).

\section{References}

Branstator G (2002) Circumglobal teleconnections, the jet stream waveguide, and the North

Atlantic Oscillation. Journal of Climate. 15(14):1893-910.

Copernicus Climate Change Service (C3S). 2017. ERA5: fifth generation of ECMWF atmospheric reanalyses of the global climate. Copernicus Climate Change Service Climate Data

Store (CDS), date of access. Online at: https://cds.climate.copernicus.eu/cdsapp\#!/home

Deser C, Phillips A, Bourdette V, Teng H (2012) Uncertainty in climate change projections: the role of internal variability. Climate dynamics. 38(3-4):527-46.

Ding Q, Wang B, Wallace JM, Branstator G (2011) Tropical-extratropical teleconnections in boreal summer: Observed interannual variability. J. Clim. 24, 1878-1896. doi:10.1175/2011JCLI3621.1 
Dunstone N, Scaife AA, MacLachlan C, Knight J, Ineson S, Smith D, Thornton H, Gordon M, McLean, Palin E, Hardiman S, Walker B (2018) Predictability of European winter 2016/2017. Atmospheric Science Letters, 19(12). https://doi.org/10.1002/asl.868

Döscher et al. (2020) The EC-Earth3 Earth System Model for the Climate Model Intercomparison Project 6. Submitted to Geoscientific Model Development (GMD). December 2020.

Efron B, Tibshirani R (1991) Statistical data analysis in the computer age. Science, 253(5018):390-5.

Feldstein SB (2003) The dynamics associated with equatorial atmospheric angular momentum in an aquaplanet GCM. Journal of the atmospheric sciences. 60(15):1822-34.

Fuentes-Franco R, Koenigk T (2020) Identifying remote sources of interannual variability for summer precipitation over Nordic European countries tied to global teleconnection wave patterns, Tellus A: Dynamic Meteorology and Oceanography, 72:1, 1-15, DOI: 10.1080/16000870.2020.1764303

Gastineau G, Frankignoul C (2015). Influence of the North Atlantic SST variability on the atmospheric circulation during the twentieth century. Journal of Climate, 28(4), 1396- 1416.

https://doi.org/10.1175/JCLI-D-14-00424.1

Hoskins BJ and Ambrizzi T (1993) Rossby wave propagation on a realistic longitudinally varying flow. J. Atmos. Sci. 50, 1661-1671.

Holton JR, Hakim GJ (2004). An introduction to dynamic meteorology. Waltham, MA: Academic Press.

Knight JR, Maidens A, Watson PA, Andrews M, Belcher S, Brunet G, Fereday D, Folland CK, Scaife AA, Slingo J (2017). Global meteorological influences on the record UK rainfall of winter 2013-14.

Environmental Research Letters. 12(7):074001.

Kornhuber K, Petoukhov V, Petri S, Rahmstorf S, Coumou D (2017) Evidence for wave resonance as a key mechanism for generating high-amplitude quasi-stationary waves in boreal summer. Climate Dynamics. 49(5-6):1961-79.

Kornhuber K, Osprey S, Coumou D, Petri S, Petoukhov V, Rahmstorf S, Gray L (2019) Extreme weather events in early summer 2018 connected by a recurrent hemispheric wave-7 pattern. Environmental Research Letters. 14(5):054002.

Kornhuber K, Coumou D, Vogel E, Lesk C, Donges JF, Lehmann J, Horton RM (2020) Amplified Rossby waves enhance risk of concurrent heatwaves in major breadbasket regions. Nature Climate Change, $10(1): 48-53$.

Lavergne T, Sørensen AM, Kern S, Tonboe R, Notz D, Aaboe S, Bell L, Dybkjær G, Eastwood S, Gabarro C, Heygster G. Version 2 of the EUMETSAT OSI SAF and ESA CCI sea-ice concentration climate data records. The Cryosphere. 2019 Jan 9;13(1):49-78. 
Li X, Lu R, Greatbatch RJ, Li G, Hong X (2020). Maintenance Mechanism for the Teleconnection Pattern over the High Latitudes of the Eurasian Continent in Summer. Journal of Climate. 33(3):1017-30.

Li RK, Woollings T, O'Reilly C, Scaife AA (2020) Tropical atmospheric drivers of wintertime European precipitation events. Quarterly Journal of the Royal Meteorological Society. 146(727):780-94.

Neddermann NC, Müller WA, Dobrynin M, Düsterhus A, Baehr J (2019) Seasonal predictability of European summer climate re-assessed. Clim. Dyn. 53, 3039-3018. doi:10.1007/s00382-019-04678-4

Nie Y, Zhang Y, Yang XQ, Ren HL. (2019) Winter and Summer Rossby Wave Sources in the CMIP5 Models. Earth and Space Science. 6(10):1831-46.

O'Reilly CH, Woollings T, Zanna L, Weisheimer A (2018) The impact of tropical precipitation on summertime Euro-Atlantic circulation via a circumglobal wave train. J. Clim. 31, 6481-6504. doi:10.1175/JCLI-D-17-0451.1

Petoukhov V, Rahmstorf S, Petri S, Schellnhuber HJ (2013) Quasiresonant amplification of planetary waves and recent Northern Hemisphere weather extremes. Proceedings of the National Academy of Sciences. 110(14):5336-41.

Qin J, Robinson WA (1993) On the Rossby Wave Source and the Steady Linear Response to Tropical Forcing. Journal of the Atmospheric Sciences, 50, 1819- 1823.

Saeed S, Van Lipzig N, Müller WA, Saeed F, Zanchettin, D (2014) Influence of the circumglobal wave-train on European summer precipitation. Clim. Dyn. 43, 503-515. doi:10.1007/s00382-013-1871-0

Sardeshmukh PD and Hoskins BJ (1988) The generation of global rotational flow by steady idealised tropical divergence. Journal of Atmospheric Sciences, 45, 1228- 1251

Scaife AA, Comer RE, Dunstone NJ, Knight JR, Smith DM, MacLachlan C, Martin N, Peterson KA, Rowlands D, Carroll EB, Belcher S (2017) Tropical rainfall, Rossby waves and regional winter climate predictions. Quarterly Journal of the Royal Meteorological Society. 143(702):1-1.

Screen JA, Francis JA (2016) Contribution of sea-ice loss to Arctic amplification is regulated by Pacific Ocean decadal variability. Nature Climate Change. 6(9):856-60.

Trenberth KE, Branstator GW, Karoly D, Kumar A, Lau N-C, Ropelewski C (1998) Progress during TOGA in understanding and modelling global teleconnections associated with tropical sea surface temperatures. Journal of Geophysical Research, 103, 14,291-14,324.

Van Oldenborgh GJ, Burgers G, Tank AK (2000) On the El Nino teleconnection to spring precipitation in Europe. Int. J. Climatol. 20, 565-574. doi:10.1002/(SICI)1097- 
Wulff CO, Greatbatch, RJ, Domeisen DI, Gollan G, Hansen F (2017) Tropical forcing of the Summer East Atlantic pattern. Geophys. Res. Lett. 44, 11166-11173

Wyser K, Koenigk T, Fladrich U, Fuentes-Franco R, Karami MP (2020). The SMHI Large Ensemble (SMHILENS) with EC-Earth. Submitted to Geoscientific Model Development (GMD). December 2020.

\section{Table}

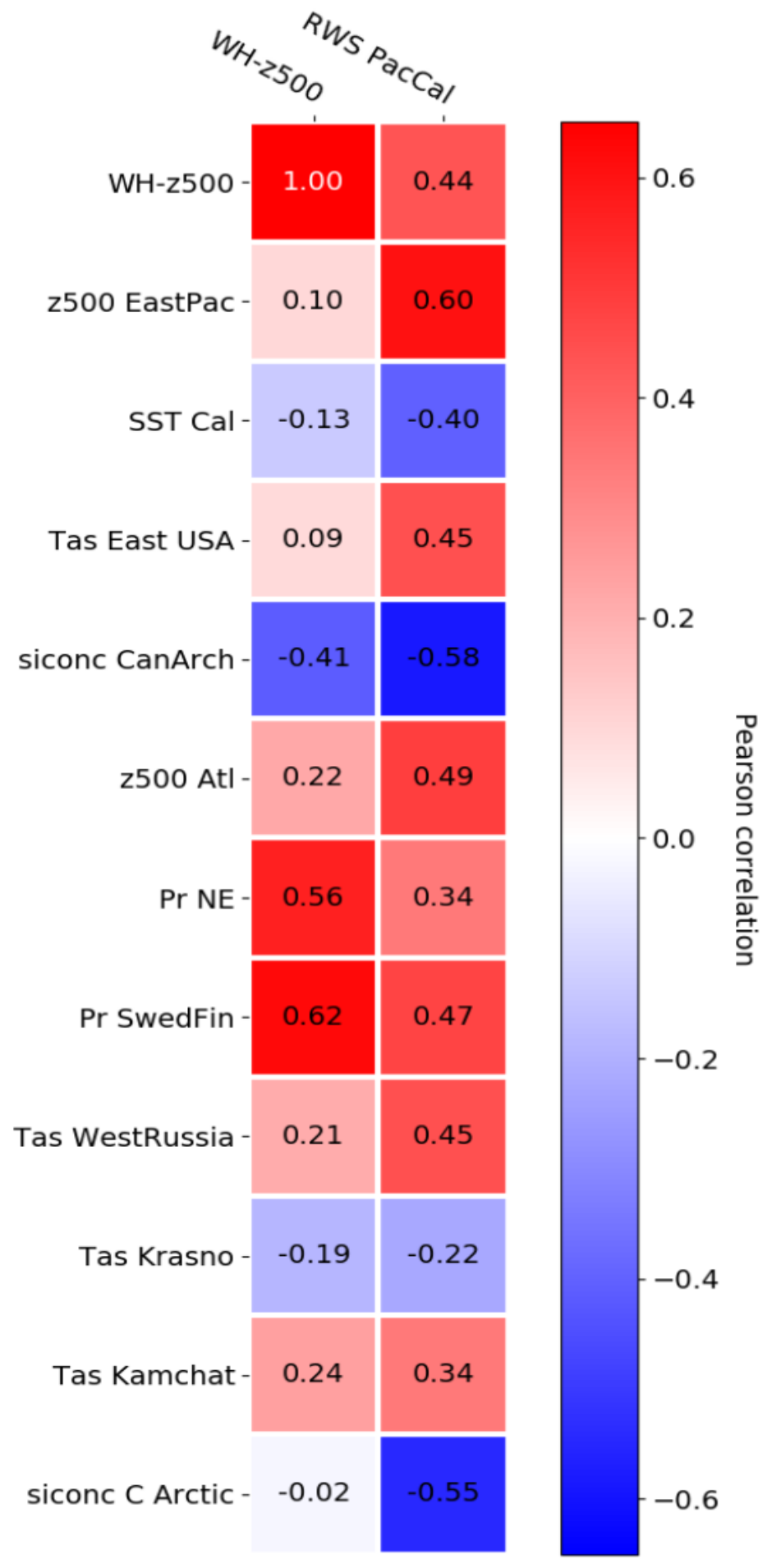


Table 1. Pearson correlation correlation between PacCal RWS, WH-z500 and different climate variables in regions that seem to have a connection with RWS. All correlations were statistically significant at 95\% level or higher (except Tas Kamchat), while only those between WH-z500 and Pr Swedfin, Pr NE, siconc CanArch, Tas Kamchat were significant. Regions were considered within the following land points:

z500 EastPac: [167.5W, 41N], [159.5W, 53.75N], [139.25W, 54.5N], [131W, 37.25N], [143W, 29N]

SST Cal: [135.25W, 45.75N], [125.75W, 47.25N], [123W, 31.5N], [141.75W, 28.25N]

Ts East ESA: [96.5W, 38.25N], [95.5W, 31.25N], [81.5W, 32.25N], [73.75W, 52.25N], [85.75W, 53.5N], [86.5W, 39.75N]

siconc CanArch: [118.75W, 80.75N], [128.75W, 71.25N], [117.75W, 72.75N], [91.25W, 73.25N], [93.75W, 80.75N], [110.75W, $76.75 \mathrm{~N}]$

z500 Atl: [26.6W, 39N],[18W,39N],[18W, 46N],[26.6W, 46N]

$\operatorname{Pr} \mathrm{NE}:[13 \mathrm{E}, 48.75],[13 \mathrm{E}, 64.75 \mathrm{~N}],[29.75 \mathrm{E}, 70.5 \mathrm{~N}],[25.5 \mathrm{E}, 62 \mathrm{~N}],[29.75 \mathrm{E}, 50.5 \mathrm{~N}]$

Pr SwedFin: [18.95E, 63.4N], [26.54E, 63N], [27.6E, 67.3N], [21.3E, 68N] as defined in Fuentes-Franco and Koenigk (2020).

Tas West Russia: [32E, 57.25N], [51E, 41.25N], [65.75E, 53.75N], [46.25E, 64.5N]

Tas Krasno: [86.2E, 62N], [86.2E, 55N], [110.5E, 55N], [110E, 62N]

Tas Kamchat: [152.3E, 51.1N], [168E, 51.1N], [171E, 64.1N], [152.4E, 64.1N]

siconc C Arctic: [30E, 80N],[30E, 90N],[180E, 90N],[180E, 80N]

\section{Figures}



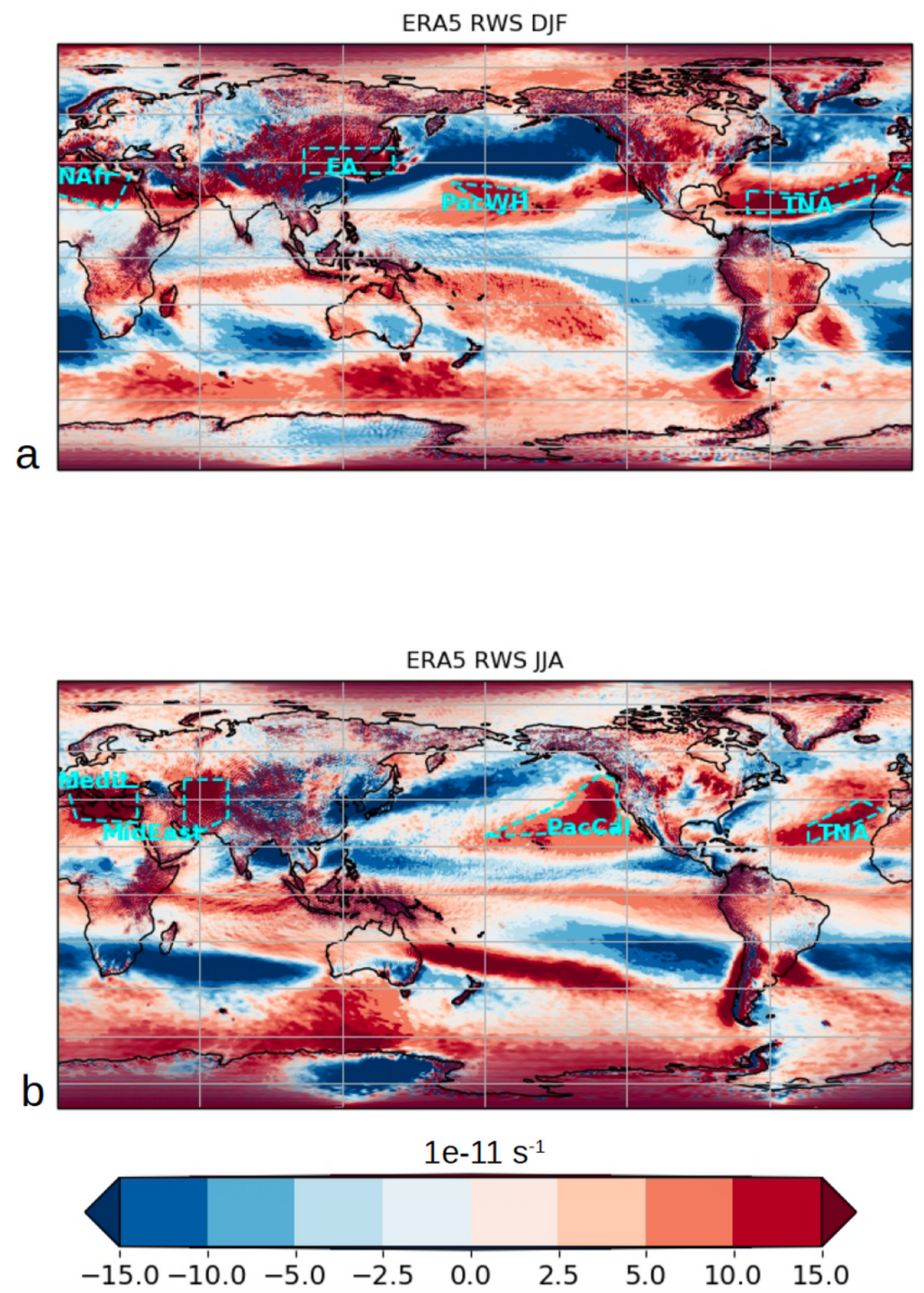

\section{Figure 1}

RWS climatology during a) DJF and b) JJA seasons. Main RWS regions are enclosed in cyan. Note: The designations employed and the presentation of the material on this map do not imply the expression of any opinion whatsoever on the part of Research Square concerning the legal status of any country, territory, city or area or of its authorities, or concerning the delimitation of its frontiers or boundaries. This map has been provided by the authors. 

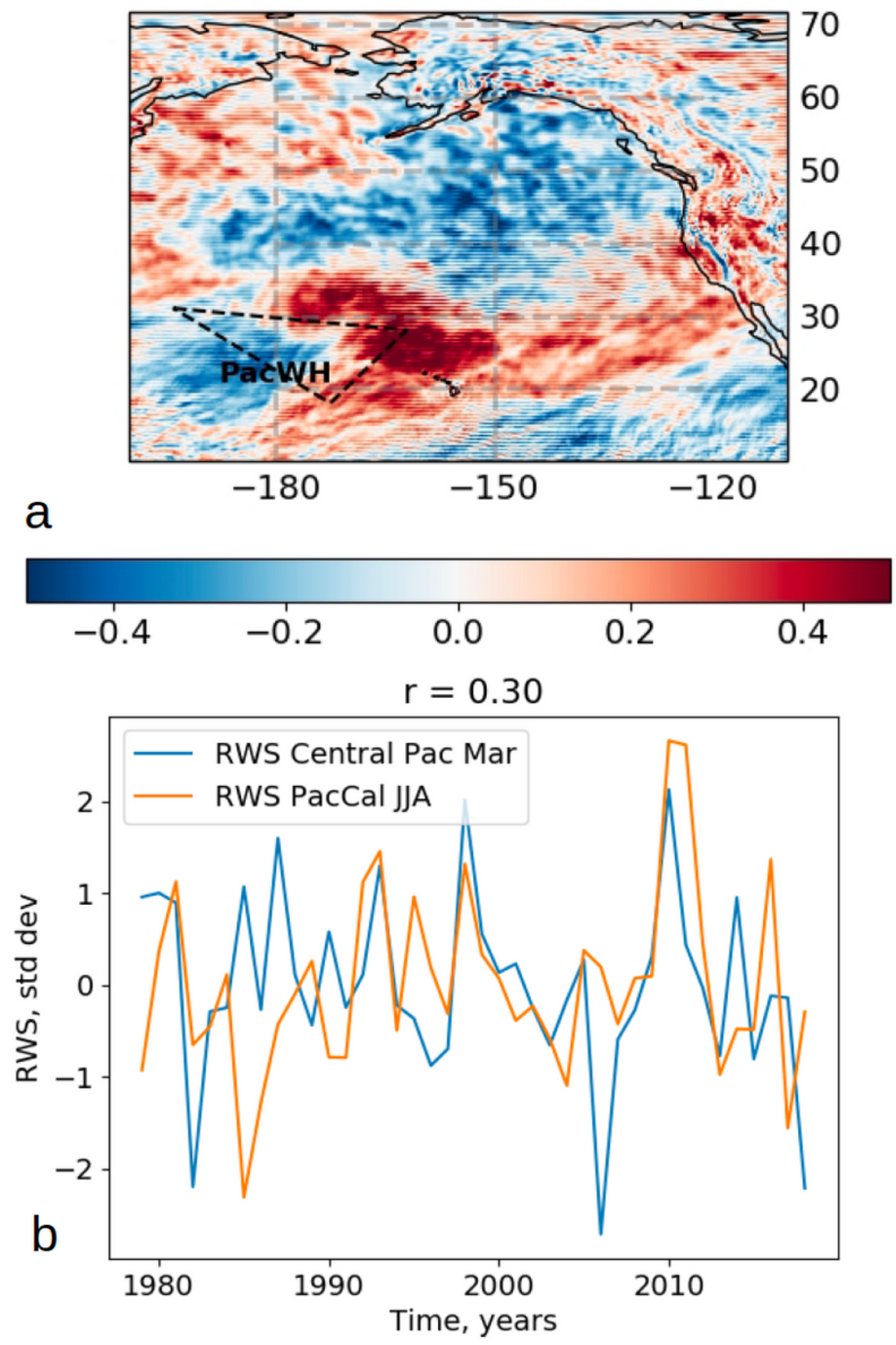

Figure 2

a) Pearson correlation between each grid point RWS during March and z500 in the region WH during March. b) Standardized time-series of the average RWS over the central Pacific within the area between longitudes $168 \mathrm{~W}$ and $150 \mathrm{~W}$ and latitudes $22 \mathrm{~N}$ and $27 \mathrm{~N}$ during March (blue line). Standardized time-series of the average RWS over the PacCal region during JJA (orange line). The Pearson correlation between both time series is significant at $95 \%$. Note: The designations employed and the presentation of the 
material on this map do not imply the expression of any opinion whatsoever on the part of Research Square concerning the legal status of any country, territory, city or area or of its authorities, or concerning the delimitation of its frontiers or boundaries. This map has been provided by the authors.
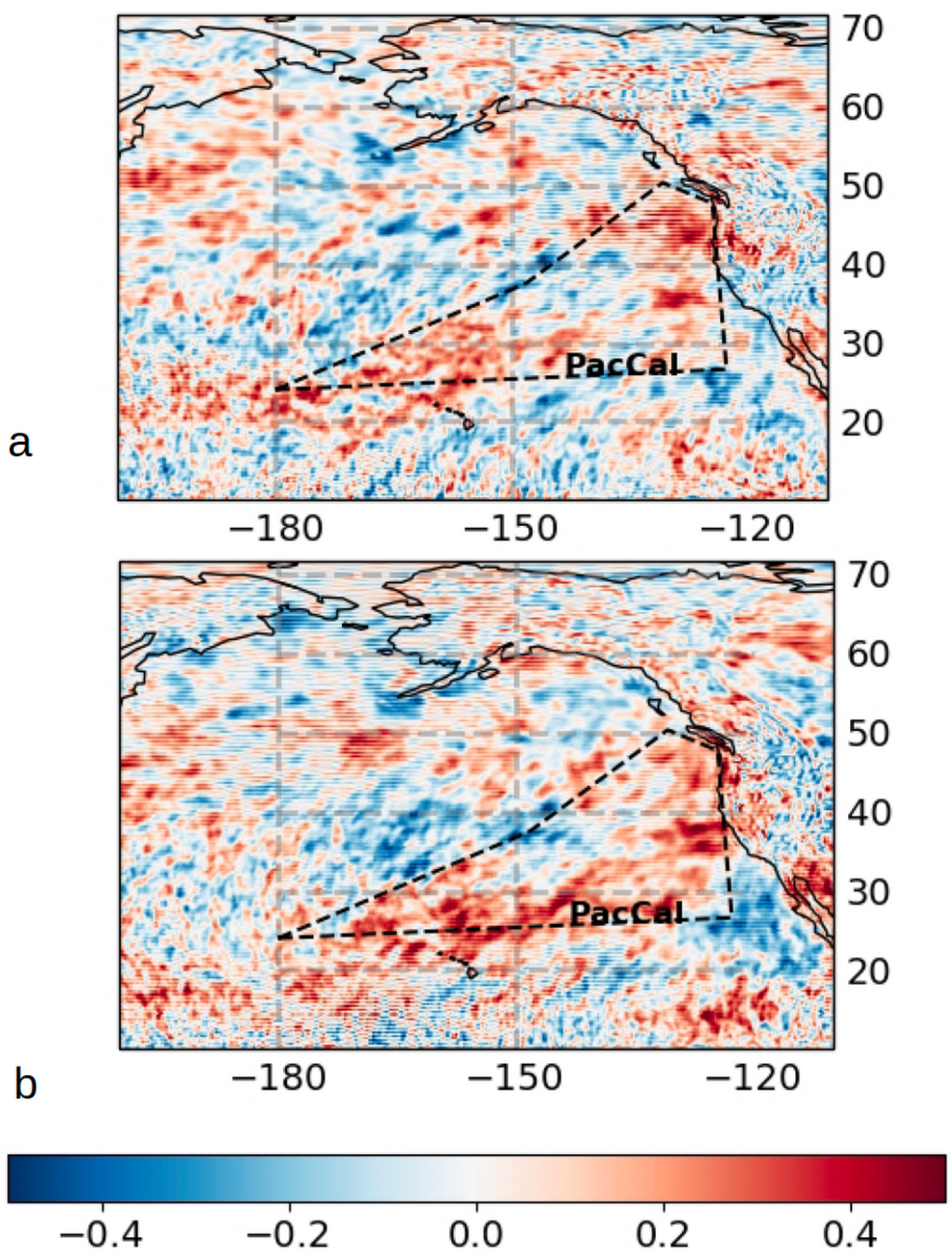

Figure 3

a) Pearson correlation between each grid point RWS during JJA and z500 in the region WH during March.

b) Pearson correlation between each grid point RWS during JJA and RWS over the central Pacific within 
the area between longitudes $168 \mathrm{~W}$ and $150 \mathrm{~W}$ and latitudes $22 \mathrm{~N}$ and $27 \mathrm{~N}$ during March. Note: The designations employed and the presentation of the material on this map do not imply the expression of any opinion whatsoever on the part of Research Square concerning the legal status of any country, territory, city or area or of its authorities, or concerning the delimitation of its frontiers or boundaries. This map has been provided by the authors.
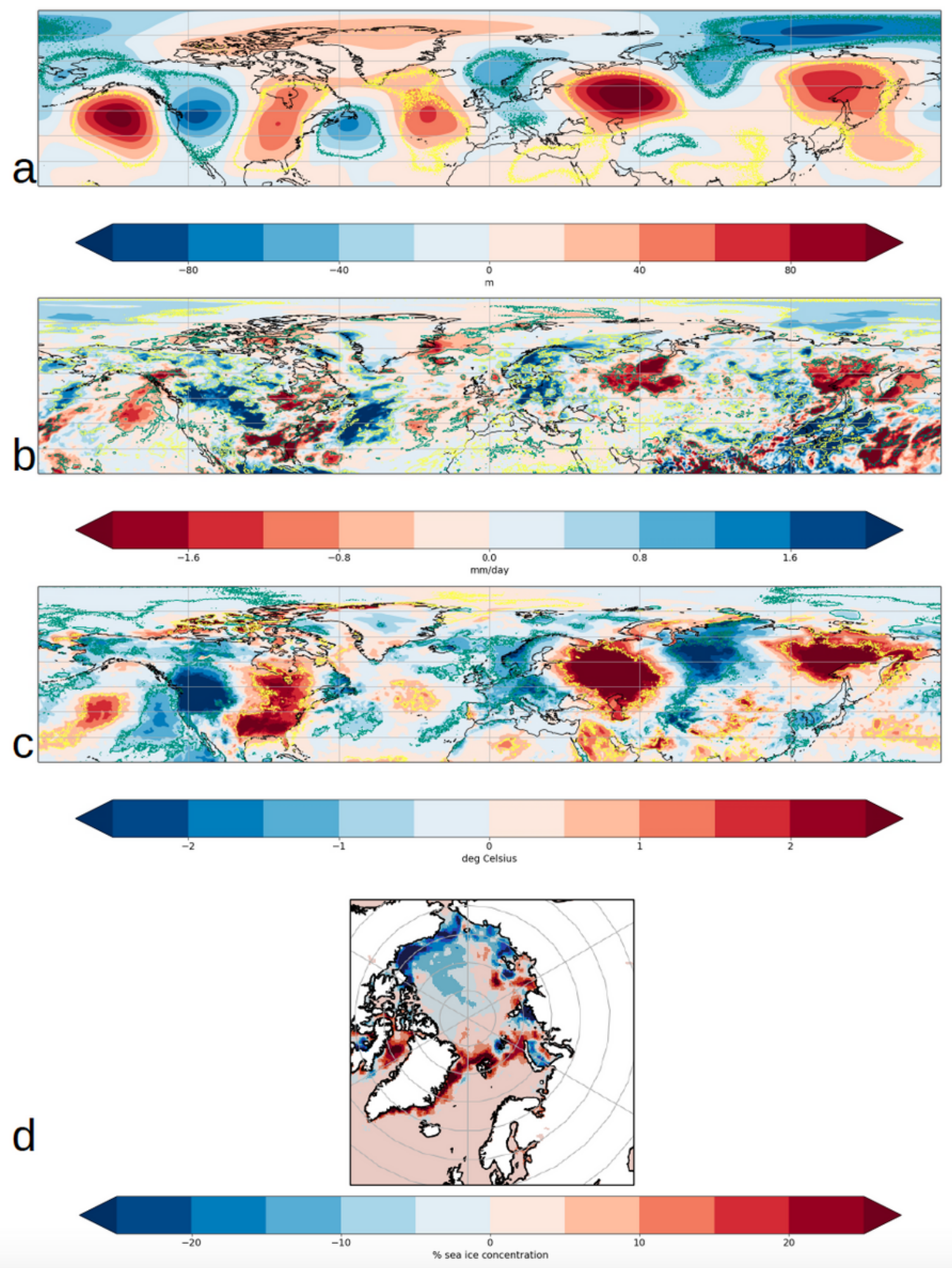

Figure 4 
a) z500 composite of PacCal RWS 90th percentile minus 10th percentile during July. b) - d) similar to a) for precipitation, surface temperature and sea ice concentration respectively. ERA5 data was used for z500, precipitation and surface temperature and OSI SAF for sea ice concentration. Note: The designations employed and the presentation of the material on this map do not imply the expression of any opinion whatsoever on the part of Research Square concerning the legal status of any country, territory, city or area or of its authorities, or concerning the delimitation of its frontiers or boundaries. This map has been provided by the authors.
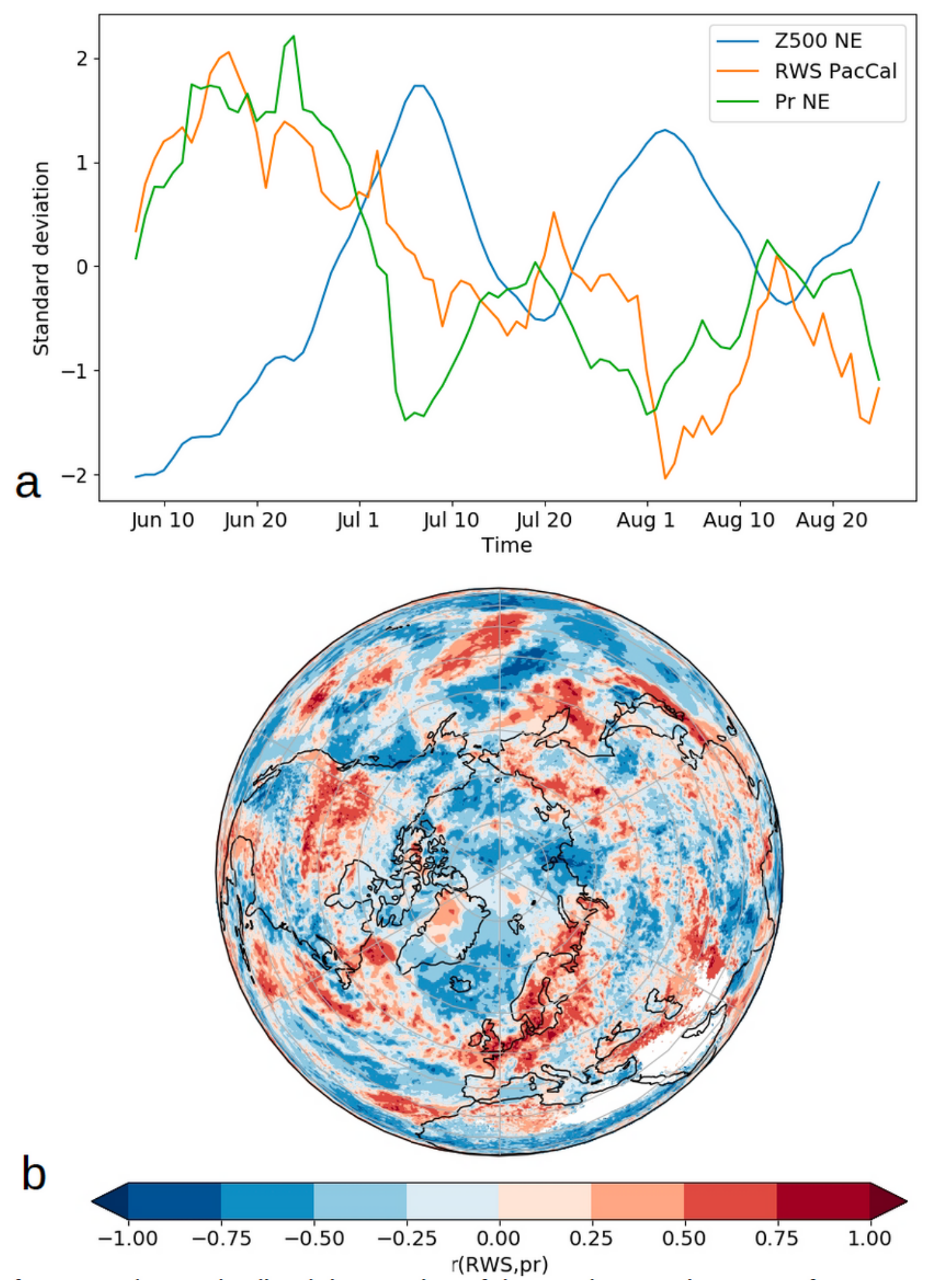


\section{Figure 5}

a) Standardized time-series of the 12 days running mean for RWS over the PacCal region, and for precipitation, z500 over Northern Europe during June, July and August of 1991. The area used for precipitation and temperature lies within the following points $1.5 \mathrm{E}, 50 \mathrm{~N}, 11 \mathrm{E}, 59 \mathrm{~N}, 28 \mathrm{E}, 59 \mathrm{~N}$ and $20 \mathrm{E}, 52 \mathrm{~N}$. Including areas of Northern France, Belgium, Netherlands, Northern Germany, Denmark, Southern Sweden, Poland, and the Baltic countries. b) Pearson correlation of PacCal RWS with global precipitation for every grid point, with a 12-days running mean during summer (JJA) of 1991. Note: The designations employed and the presentation of the material on this map do not imply the expression of any opinion whatsoever on the part of Research Square concerning the legal status of any country, territory, city or area or of its authorities, or concerning the delimitation of its frontiers or boundaries. This map has been provided by the authors. 
LENS RWS JA

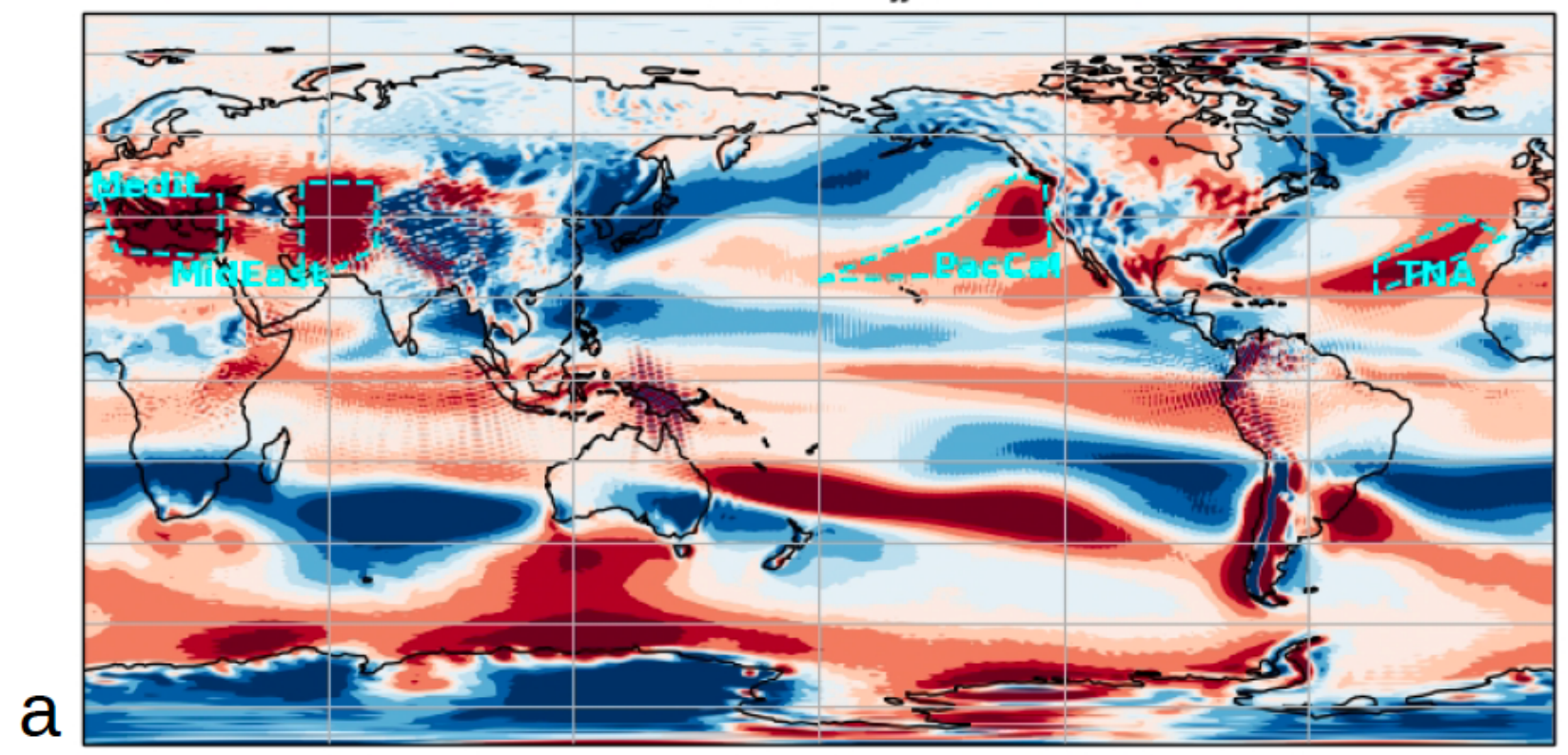

\section{LENS - ERA5 RWS JJA}
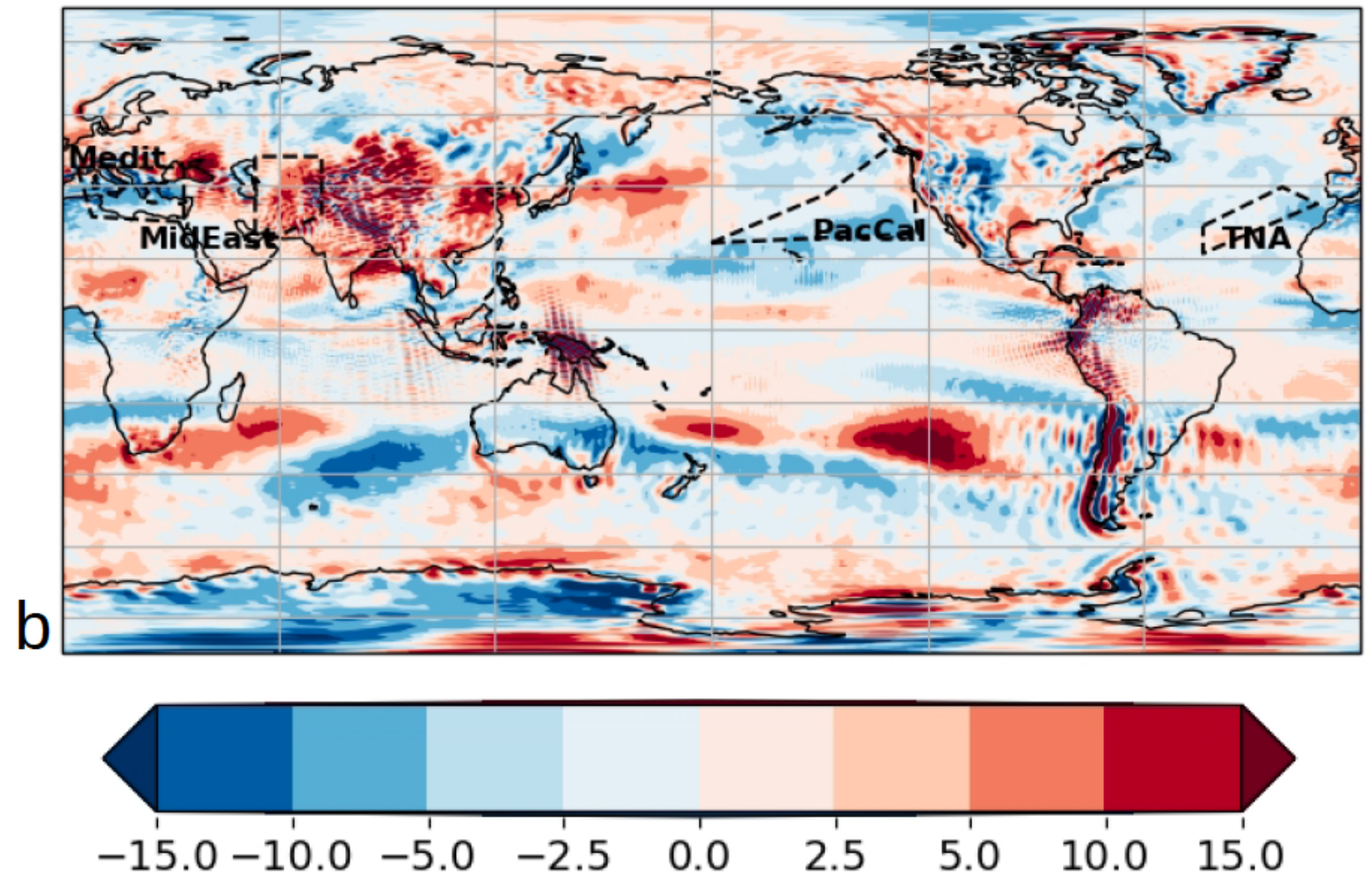

Figure 6

Average of RWS climatology during JJA season across all SMHI-LENS ensemble members. b) SMHILENS ensemble average minus ERA5 RWS climatology. As for Figure 1, the main RWS regions are enclosed in cyan. Note: The designations employed and the presentation of the material on this map do not imply the expression of any opinion whatsoever on the part of Research Square concerning the legal 
status of any country, territory, city or area or of its authorities, or concerning the delimitation of its frontiers or boundaries. This map has been provided by the authors.
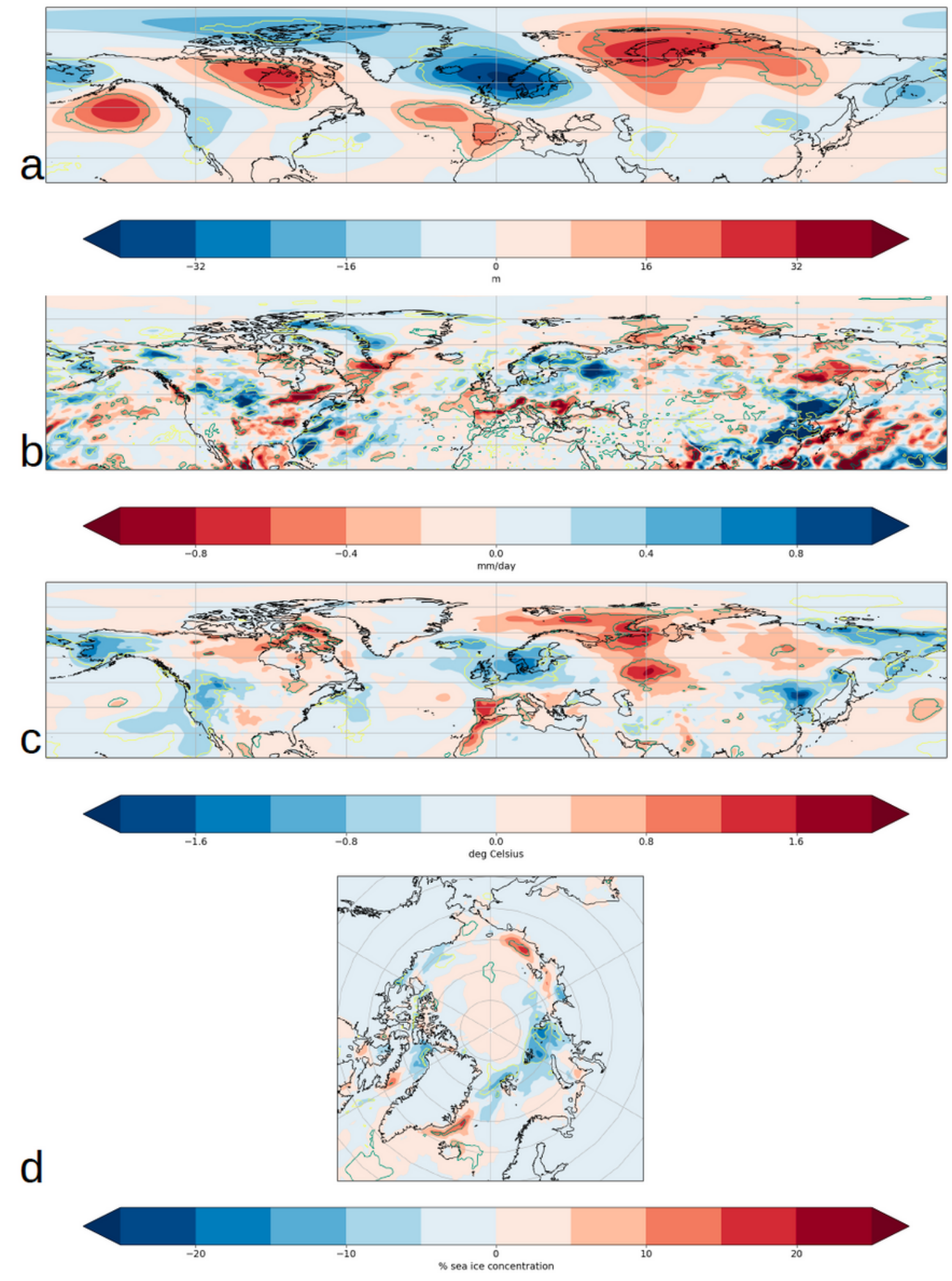

Figure 7

a) z500 composite of PacCal RWS 99th percentile minus 1st percentile during July. b) - d) similar to a) for precipitation, surface temperature and sea ice concentration respectively for the SMHI-LENS. Note: The designations employed and the presentation of the material on this map do not imply the expression of 
any opinion whatsoever on the part of Research Square concerning the legal status of any country, territory, city or area or of its authorities, or concerning the delimitation of its frontiers or boundaries. This map has been provided by the authors.
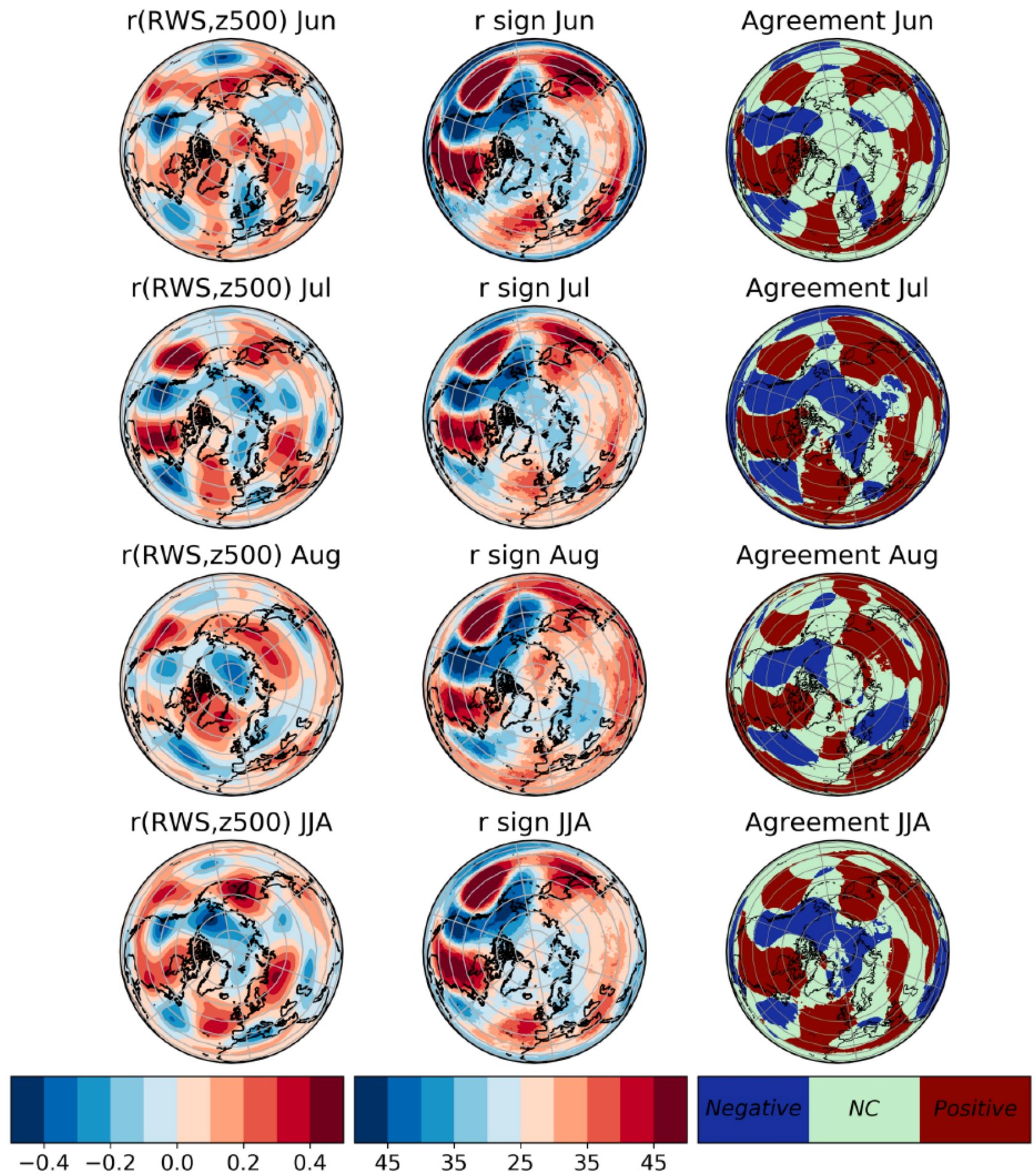

\section{Figure 8}

The left column shows the Pearson correlation of PacCal RWS with z500 for every grid point for ERA5. The middle column shows the number of SMHI-LENS ensemble members with the same sign of 
correlation between PacCal RWS with z500. The right column shows the grid points in which ERA5 and the most of SMHI-LENS, show agreement in the sign of correlation, the colorbar shows in which sign of correlation there was agreement: positive, negative or no coincidence (NC). The rows are for June, July, August and JJA seasonal mean. Note: The designations employed and the presentation of the material on this map do not imply the expression of any opinion whatsoever on the part of Research Square concerning the legal status of any country, territory, city or area or of its authorities, or concerning the delimitation of its frontiers or boundaries. This map has been provided by the authors.
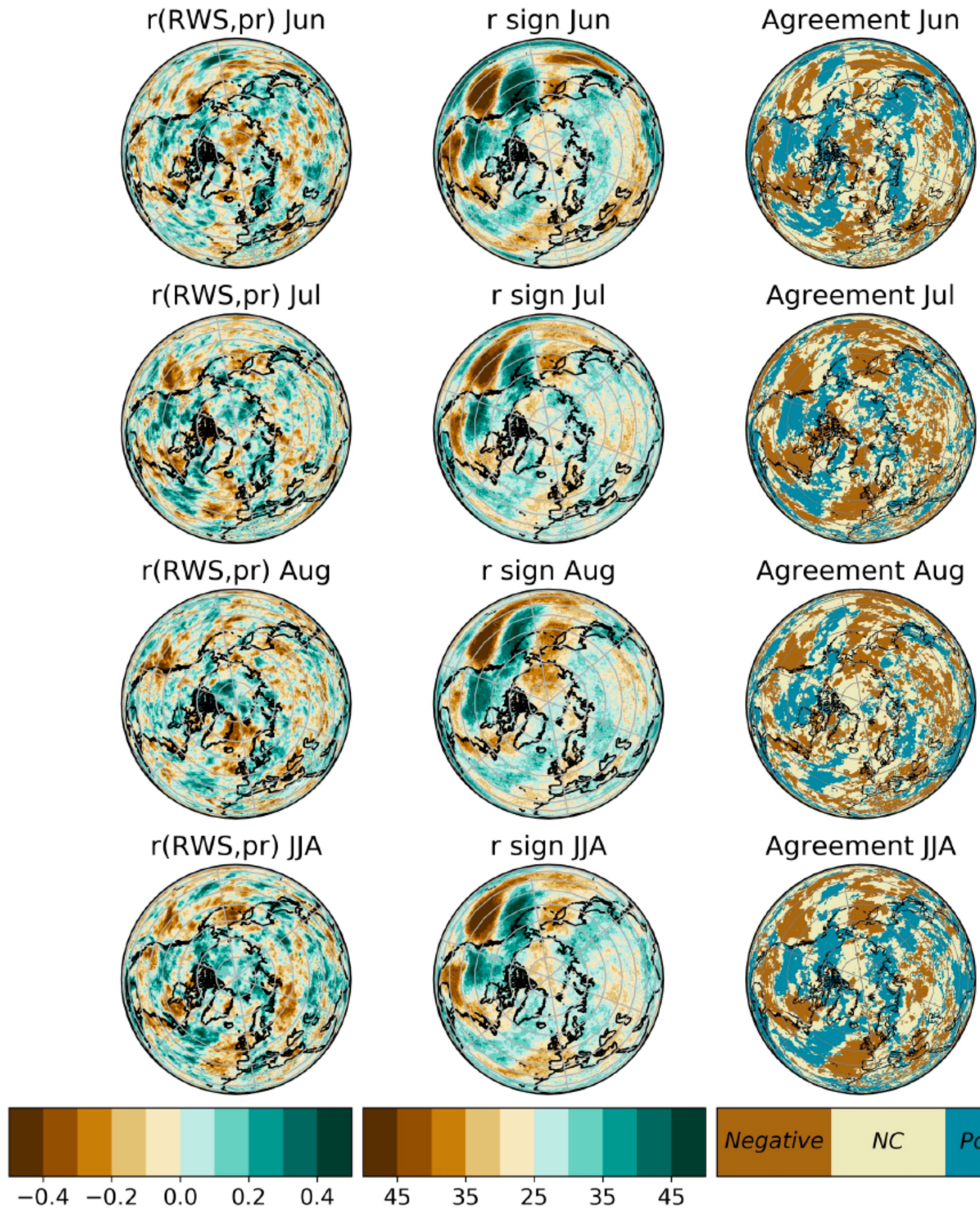

$35 \quad 25$

35

45

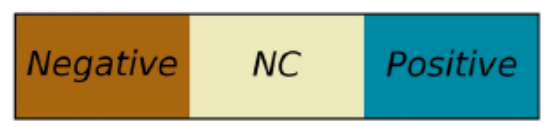




\section{Figure 9}

Similar to Figure 8 but for precipitation. Note: The designations employed and the presentation of the material on this map do not imply the expression of any opinion whatsoever on the part of Research Square concerning the legal status of any country, territory, city or area or of its authorities, or concerning the delimitation of its frontiers or boundaries. This map has been provided by the authors.
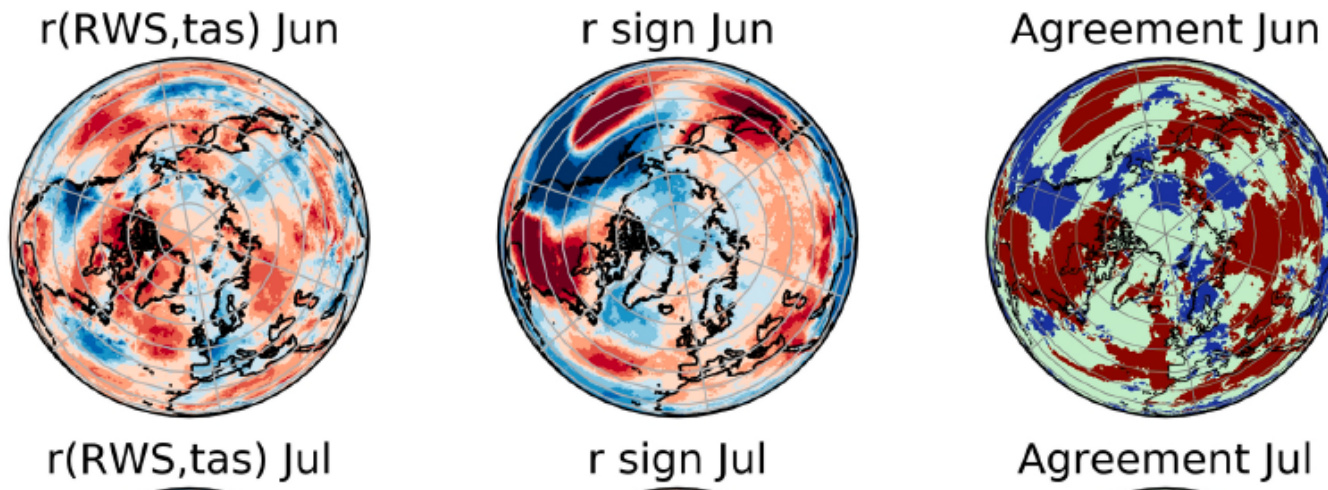

$r$ sign Jul
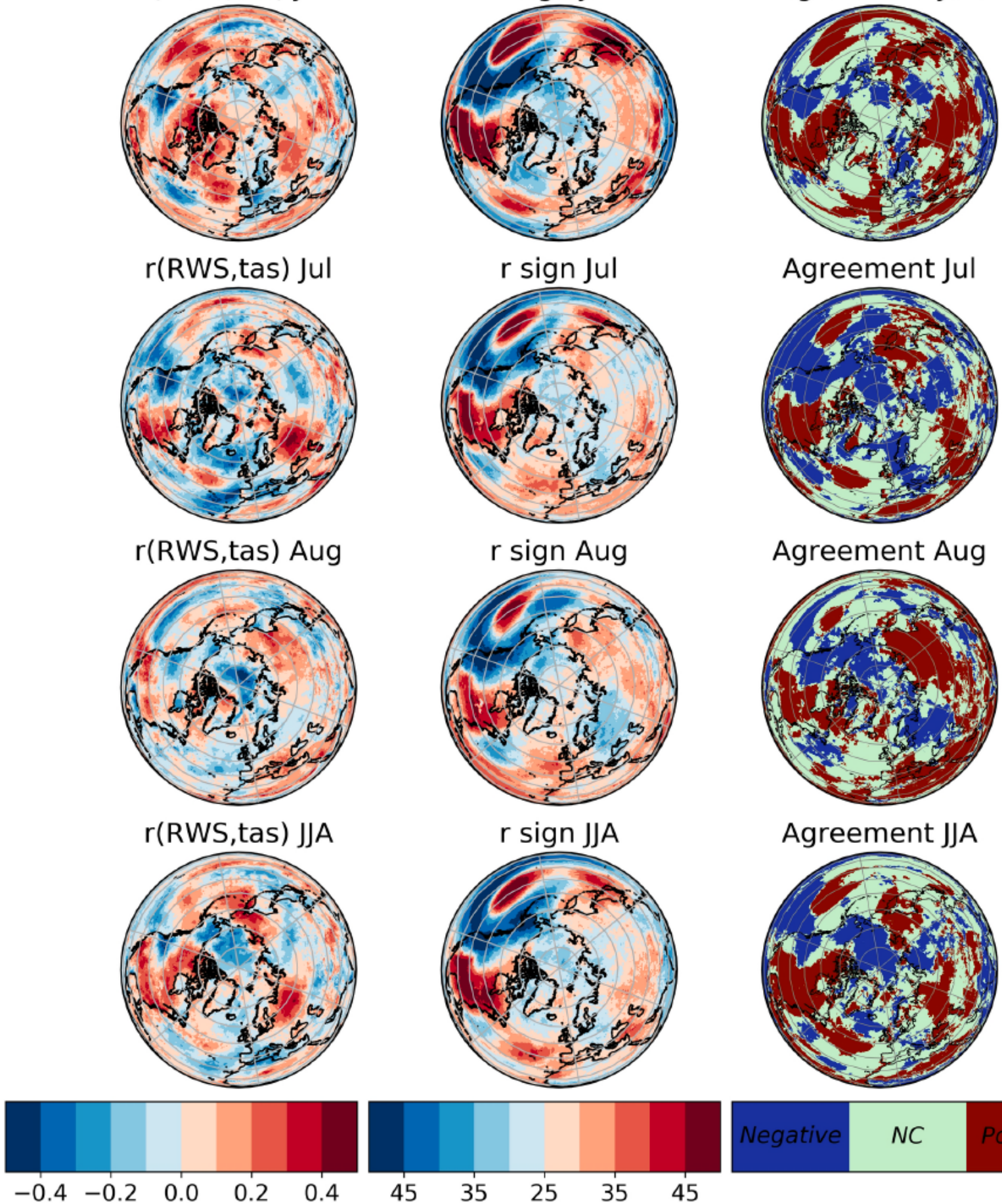

Agreement Jul

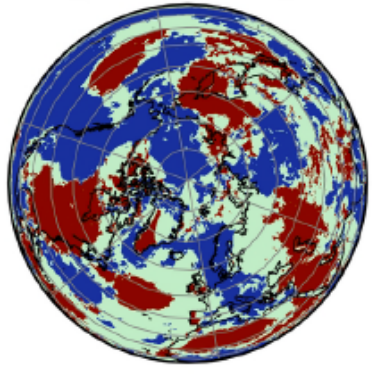

Agreement Aug

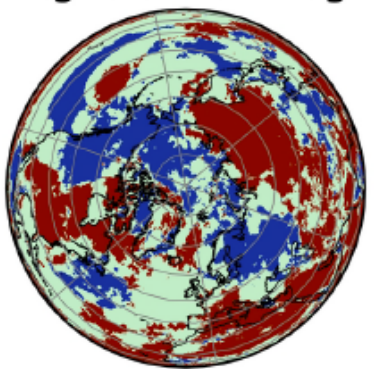

Agreement JJA

$\begin{array}{lllll}-0.4 & -0.2 & 0.0 & 0.2 & 0.4\end{array}$

$\begin{array}{lllll}45 & 35 & 25 & 35 & 45\end{array}$

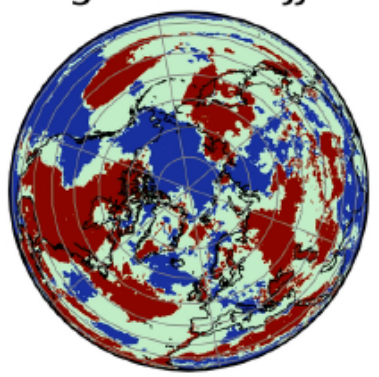

NC 
Similar to Figure 8 but for surface temperature. Note: The designations employed and the presentation of the material on this map do not imply the expression of any opinion whatsoever on the part of Research Square concerning the legal status of any country, territory, city or area or of its authorities, or concerning the delimitation of its frontiers or boundaries. This map has been provided by the authors.
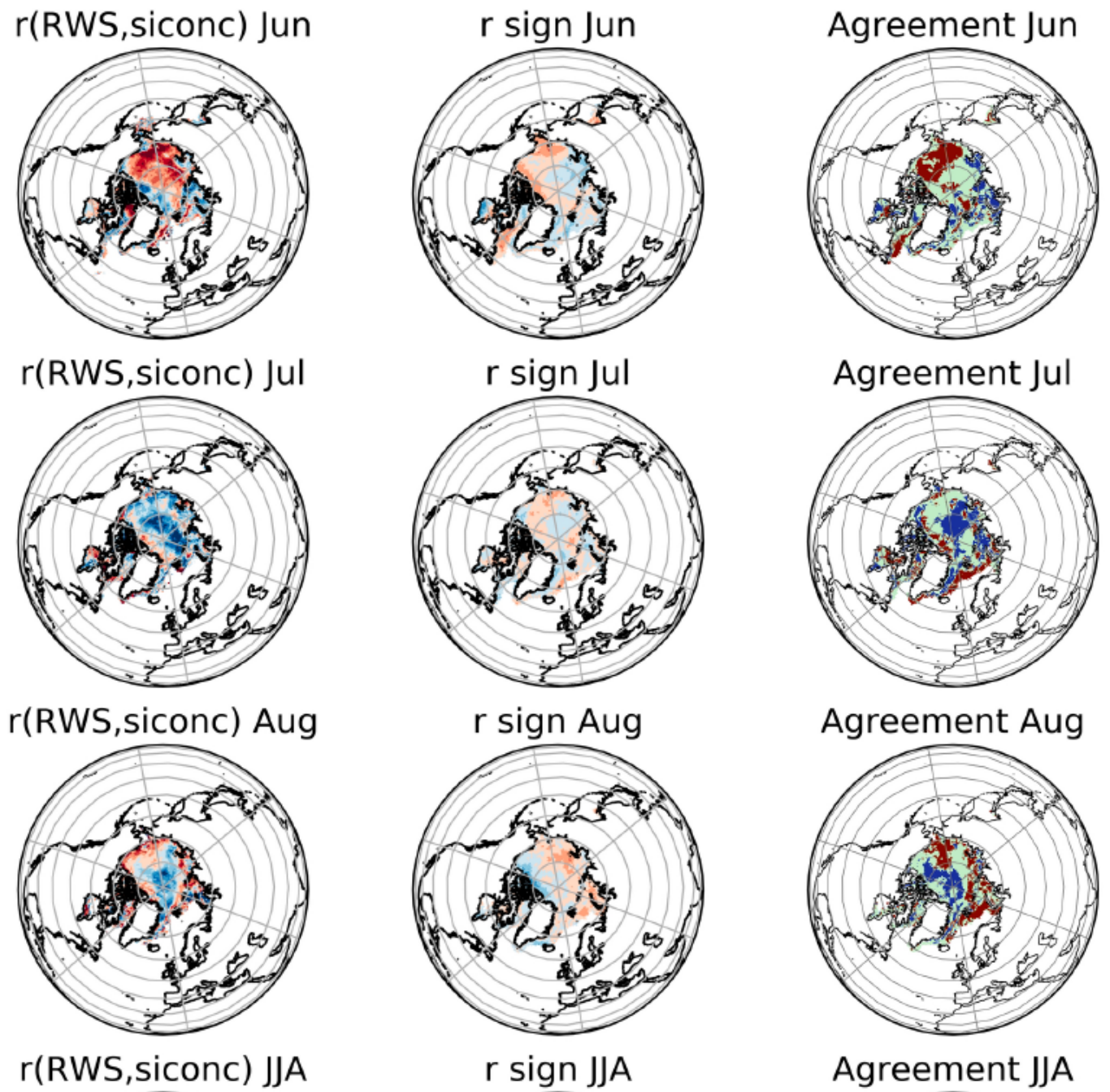

$r$ sign JJA
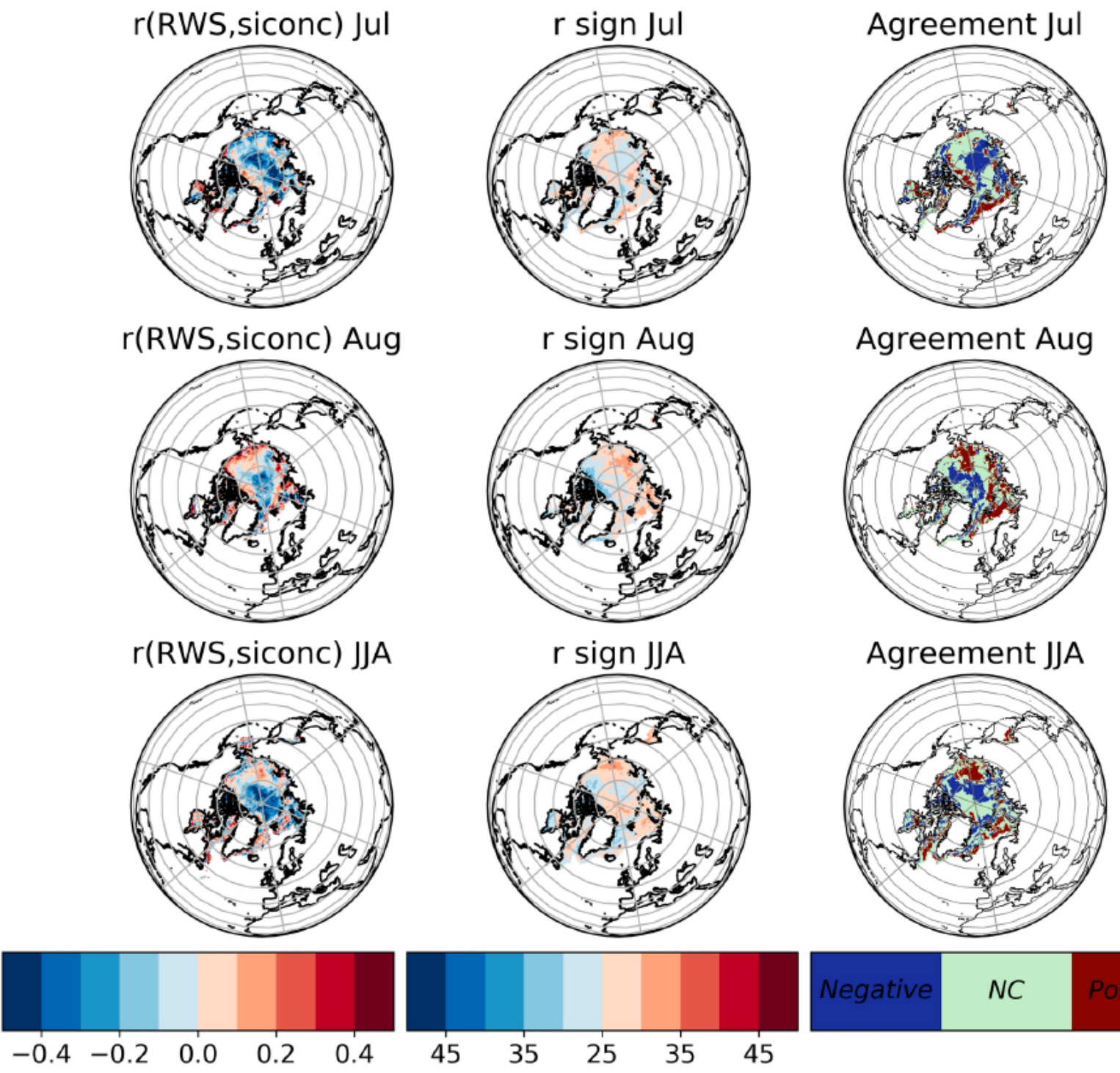

\section{NC}

\section{Figure 11}


Similar to Figure 8 but for sea ice concentration. Note: The designations employed and the presentation of the material on this map do not imply the expression of any opinion whatsoever on the part of Research Square concerning the legal status of any country, territory, city or area or of its authorities, or concerning the delimitation of its frontiers or boundaries. This map has been provided by the authors.
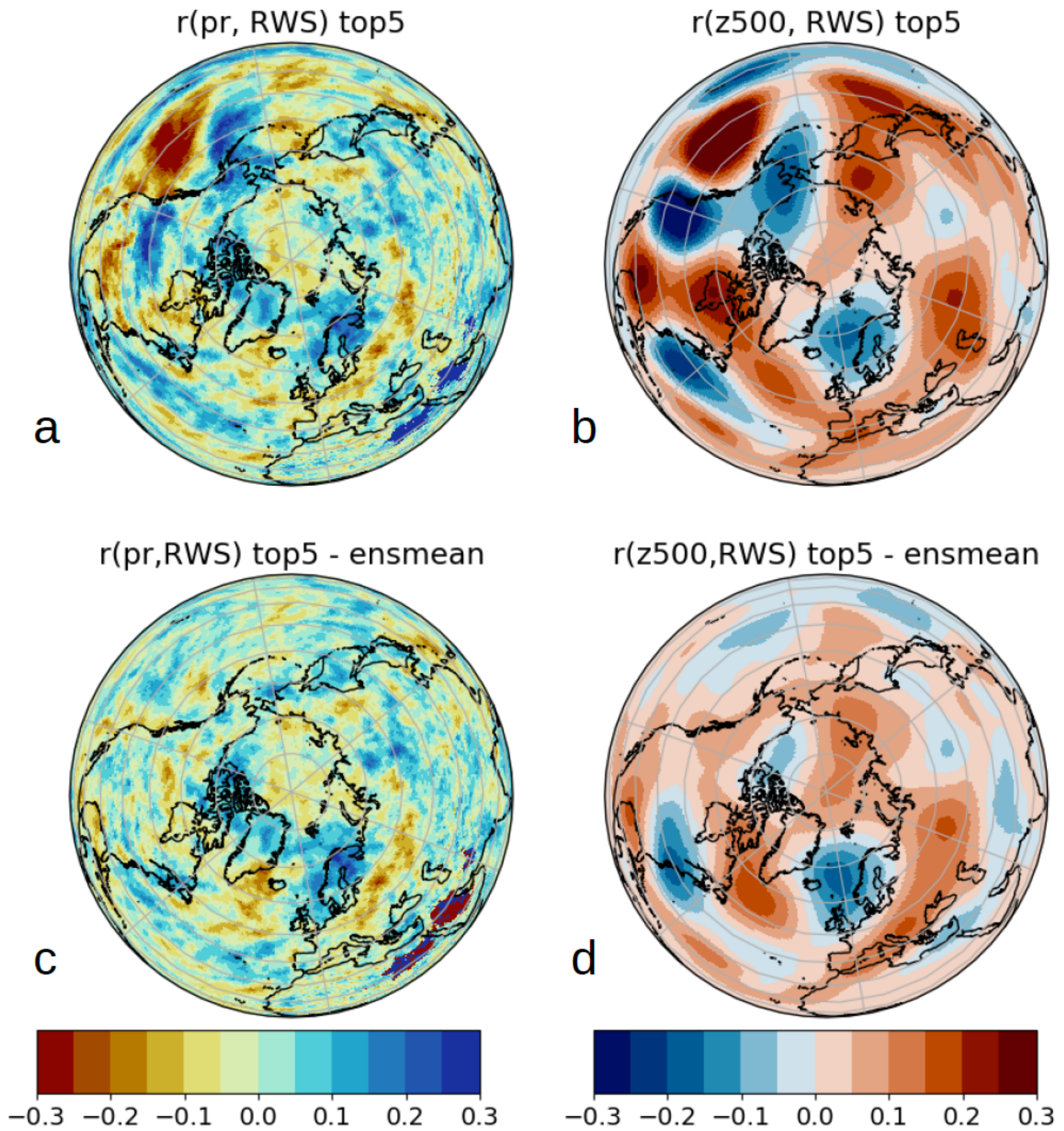

Figure 12 
Average correlation between PacCal RWS and a) precipitation for the top5 ensemble members during July. b) similar to a) for z500. Differences in mean correlation patterns between top 5 and whole ensemble mean for $\mathrm{c}$ ) precipitation and d) $\mathrm{z} 500$. Note: The designations employed and the presentation of the material on this map do not imply the expression of any opinion whatsoever on the part of Research Square concerning the legal status of any country, territory, city or area or of its authorities, or concerning the delimitation of its frontiers or boundaries. This map has been provided by the authors.
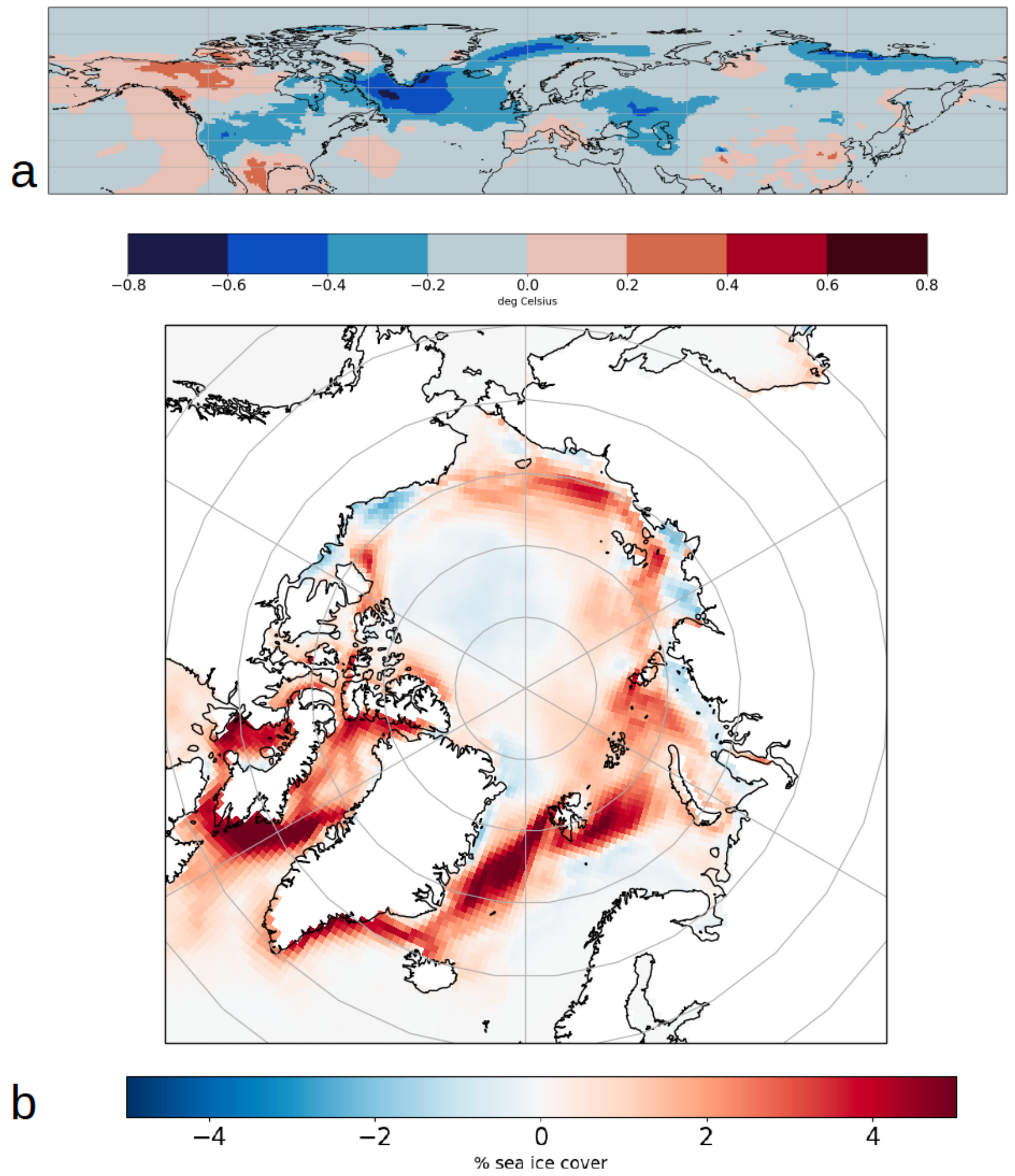

Figure 13 
Climatological differences between the mean of 5 ensemble members showing the lowest MAE in precipitation (top5) and the mean of the whole ensemble for a) surface temperature and b) sea ice concentration. The whole 1970-2014 period was used to calculate the climatology. Note: The designations employed and the presentation of the material on this map do not imply the expression of any opinion whatsoever on the part of Research Square concerning the legal status of any country, territory, city or area or of its authorities, or concerning the delimitation of its frontiers or boundaries. This map has been provided by the authors.
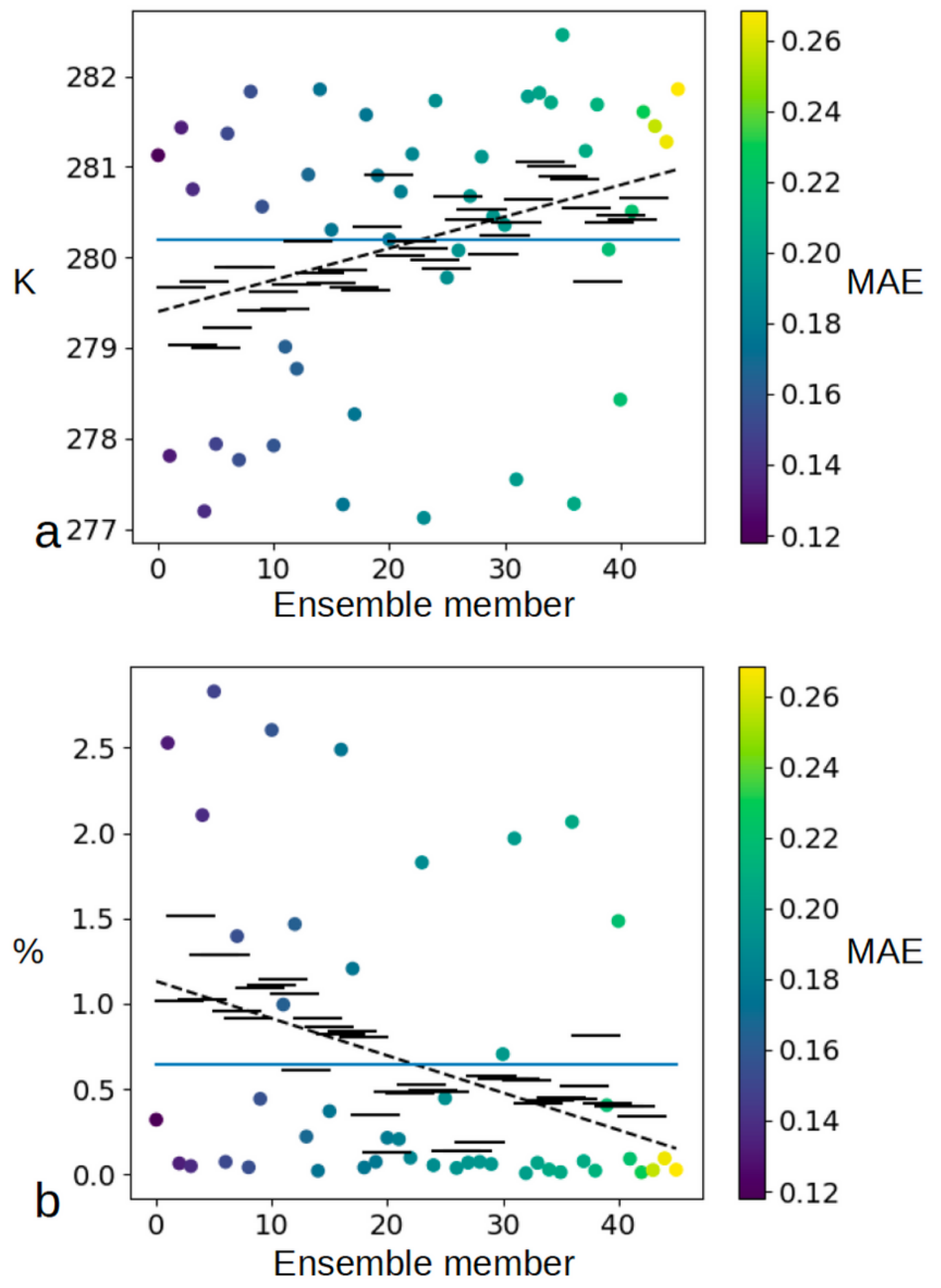


\section{Figure 14}

Scatter plot of a) surface temperature over the North Atlantic and ensemble members sorted by mean absolute error (MAE) of correlation between precipitation and RWS over the PacCal region during July. b) Similar to a) for sea ice concentration. The MAE was calculated by subtracting the correlation patterns of each ensemble member minus the one in ERA5 over Europe, within the region enclosed by the longitudes $2 \mathrm{E}-38 \mathrm{E}$ and latitudes $52 \mathrm{~N}$ and $72 \mathrm{~N}$. The region taken for the surface temperature and sea ice concentration is located within the box between longitudes 57W and 30W and latitudes $54 \mathrm{~N}$ and $60 \mathrm{~N} .5$ members ensemble mean is shown in black solid lines from lower to higher MAE values. The blue solid line shows the ensemble mean and the black dashed line shows the linear regression along the whole ensemble. 